\title{
Image reconstruction and characterisation of defects in a carbon fibre/epoxy composite monitored with guided
} waves

DOI:

10.1088/1361-665x/ab1359

\section{Document Version}

Accepted author manuscript

Link to publication record in Manchester Research Explorer

Citation for published version (APA):

Muller, A., Soutis, C., \& Gresil, M. (2019). Image reconstruction and characterisation of defects in a carbon fibre/epoxy composite monitored with guided waves. Smart Materials \& Structures. https://doi.org/10.1088/1361$665 x / a b 1359$

\section{Published in:}

Smart Materials \& Structures

\section{Citing this paper}

Please note that where the full-text provided on Manchester Research Explorer is the Author Accepted Manuscript or Proof version this may differ from the final Published version. If citing, it is advised that you check and use the publisher's definitive version.

\section{General rights}

Copyright and moral rights for the publications made accessible in the Research Explorer are retained by the authors and/or other copyright owners and it is a condition of accessing publications that users recognise and abide by the legal requirements associated with these rights.

\section{Takedown policy}

If you believe that this document breaches copyright please refer to the University of Manchester's Takedown Procedures [http://man.ac.uk/04Y6Bo] or contact uml.scholarlycommunications@manchester.ac.uk providing relevant details, so we can investigate your claim.

\section{OPEN ACCESS}




\title{
Image reconstruction and characterisation of defects in a carbon fibre/epoxy composite monitored with guided waves
}

\author{
Aurelia MULLER ${ }^{*}$, Constantinos SOUTIS $^{1}$, Matthieu GRESIL ${ }^{2}$. \\ ${ }^{1}$ Aerospace Research Institute, University of Manchester, Sackville Street, Manchester. M139PL, UK. \\ ${ }^{2}$ i-Composites lab, School of Materials, University of Manchester, Sackville Street, Manchester, M139PL, UK. \\ *Corresponding authors: aurelia.muller@postgrad.manchester.ac.uk; matthieu.gresil@manchester.ac.uk
}

Keywords: structural health monitoring, guided waves, Lamb waves, Total Focusing Method, CFRP, image analysis, shape factors, defect quantification, defect classification.

\begin{abstract}
In this extensive experimental study, the structural health monitoring (SHM) of a large $1 \mathrm{~m} \times 1 \mathrm{~m}$ carbon fibre reinforced polymer (CFRP) laminate was performed using guided waves. Multiple hole- and crack- type defects were induced in the structure and the guided wave signals were collected using a circular network of piezoelectric disc transducers permanently bonded to the structure. Images representing each damage state of the composite plate were obtained by applying the TFM (total focusing method with full matrix capture) on guided wave signals. Several variations in the image reconstruction algorithm were investigated by using two different baselines pristine signals or signals collected during the last damage state-, processing only the positive amplitude by implementing a lower limit threshold and normalising the signals. The algorithms' ability to detect and localise multiple defects, inside and outside the array, including holes as small as $2 \mathrm{~mm}$ in diameter, was evaluated. TFM images, involving the use of a lower threshold limit in the signal processing, resulted in more accurate detection. In addition, images obtained using both types of baseline provided complementary information leading to increased confidence in the system. All defects in the plate were detected and located even in the presence of multiple defects. Also, regions corresponding to crack- and hole-type of defects in the resulting images were identified, quantified and differentiated using geometric circularity and eccentricity shape factors. This ability of accurately identifying multiple defects and reducing location error are important contributions in the effort of establishing a reliable SHM system for multi-layered composite structures.
\end{abstract}

\section{Introduction}

Guided waves have gained considerable interest in the field of structural health monitoring (SHM) due to their potential of identifying barely visible impact damage that could improve inspection and maintenance of composite parts [1,2]. Lamb waves (a type of guided waves) are 
ultrasonic dispersive waves that propagate in thin, plate-like structure, their propagation is often affected by the presence of damage making them suitable for structural inspection applications [35]. The defect identification process generally involves a comparison between guided wave signals affected by the damage and their corresponding baseline (collected when the material was in its pristine undamaged condition) [2].

SHM involves the use of permanently bonded or embedded sensing systems in order to regularly (or continuously) inform on the integrity of the structure and predict its remaining lifespan [6]. Research on various SHM methods and their implementation have been conducted in many engineering fields including aerospace, civil engineering and renewable energy $[2,7,8]$. In addition to guided waves, other methods for monitoring aerospace structures have been investigated, such as vibration analysis, optical-fibre sensors or Eddy-current [7,9]. However, the transition from laboratory experiment to in-field implementation of an SHM system is relatively slower in aerospace compared to other industries. One major reason for this is the extent of the design restrictions dictated by complex specifications and safety standards in aircraft design [5]. This difficulty is further amplified in the case of new technology for which the certification and validation tests are yet to be defined by relevant aerospace authorities [10]. Overall, as Pfieffier and Wevers hilghlighted [9], when an SHM system reaches maturity (which implies an airworthy, reliable, durable and cost effective system) it is likely to provide incentive to its in field implementation. In this context, the development of a comprehensive system that is practical for the end-users (with automated results analysis, damage characterisation, and prediction) could enhance reliability and reduce the cost engendered by training operators. In recent years, several studies focused on identifying damage using guided wave signals collected in metals and composites [1115]. Previous studies have shown that image reconstruction techniques such as the Total Focusing Method with full matrix capture can detect discontinuities by combining the information from multiple signals obtained from an array of sensors $[11,14,16,17]$. However there is still difficulty in establishing the reliability of the system. In addition few of these studies discussed methods for analysing and quantifying regions identified as damaged [14,16,18]. In addition, a novel imaging method based on Lamb wave focusing and pulse-echo sensing configuration that could improve resolution was recently proposed [19].

In this paper the total focusing method with full matrix capture was applied to guided wave signals collected in a carbon fibre/epoxy laminate using a circular array of piezoelectric transducers. This image reconstruction algorithm was used to process data recorded at different damage states of the structure (including from a single hole to multiple holes and cracks). Several processing scenarios were investigated in order to find which was most adequate for identifying defects. The following scenarios were examined: (1) the effect of normalising the input data; (2) using a baseline of either the material in its pristine state or using a baseline defined by its previously damage state; (3) the effect of thresholding negative or positive data contained in each signal during the image 
reconstruction process. Finally, a rigorous method is proposed to quantify and classify the images of the damaged region using geometric circularity and eccentricity shape factors, which is considered as original contribution to the problem of damage localization and damage size estimation that could lead to a more reliable SHM system.

\section{Guided waves and image reconstruction}

\subsection{Guided waves and piezoelectric transducers}

The ability of guided waves to travel long distance and detect damage in metals or composites has been widely documented [3,17,20-22]. Guided waves can display different modes of propagation: symmetric with an in-plane propagation; and anti-symmetric with an out-of-plane propagation. The dispersivity of guided waves means that several modes with different wave speeds can co-exist at a given excitation frequency. Their propagation also varies with the thickness and the nature of the propagation medium. In the presence of a defect the waves undergo attenuation and scattering, which can include mode conversion [23] that adds complexity to the interpretation of signals when identifiying damage. In order to minimise this issue, guided waves are often tuned to a specific mode by careful selection of the excitation frequency [11,17]. Previous studies have shown that change in temperature (as low as $0.5^{\circ} \mathrm{C}$ ) [14] or structural loading [18] can also alter the wave propagation.

PZT (Lead ziconate titanate) disc transducers are often used in SHM applications. When bonded to the surface of a material, PZT transducers have a double functionality: they can generate guided waves in the propagation medium and they can sense the propagated waves [5]. Thereby, arrays of PZT transducers can successively work in pitch and catch configuration where each transducer can operate as both wave-emmiter and wave-receiver [21]. Such a configuration is well suited to damage detection and image reconstruction of a large inspection area. However, one issue with the use of PZT tranducer is the inconsistent amplitude variation that can be found between the recorded guided wave signals (within a same array and for the same excitation frequency), which can ultimately reduce the clarity of the reconstructred image. The received signals' amplitude generally varies with the distance between the transmitting and receiving PZT transducer due to damping of the propagation medium. However, the relation between signal amplitude and distance between transducers has been reported to follow an exponential decay trend [5], hence this is not the source of the inconsistency. The main issue occurs when waves that propagated over a similar distance, but recorded by different transducers result in signals with different amplitudes.

This can be caused by inconsistencies between the bonding of PZT transducers constituting the array. Based on the study by Khodaei et al. [24], variation in the glue layer thickness that bonds the PZT transducer to the investigated component can affect its ability to transmit or record waves. As this issue is difficult to avoid without an automated positioning and bonding of the transducers, the 
current investigation studies the impact of normalising the signal to reduce noise in the final reconstructed image.

\subsection{Image reconstruction with total focusing method}

The image reconstruction technique employed in this paper is based on the Total Focusing Method (TFM) with full matrix capture. This method was first applied on guided waves signals by Michaels [16] and has since been used in other studies [11,14,17,18].

This method enables imaging defects from guided waves signals collected in pitch and catch configuration using piezoelectric sensors. In order to reconstruct an image using this technique, as well as most sum and delay beam forming techniques, two types of input signal data are required: the baseline signals and the damaged state signals [11,14,16-18]. The baseline data used is often representative of the materials in its pristine (undamaged) condition corresponding to the first inspection. The damaged state signals are collected at some point after the baseline, and carry information regarding to defects recently acquired by the material. However, the baseline can, in fact, be any data set representative of an earlier damaged state that was collected before the latest inspection.

The preliminary signals processing applied to the guided wave signals before performing the TFM varies between studies reported in the literature [11,14,16-18]. Some of these variations are summarized in Table 1. Often the data input for the image reconstruction algorithm is a subtraction of the envelope of the baseline signals from the envelope of the most recently acquired damaged state signals leading to residual signals. The envelopes or the signals are often filtered to remove potential noise in order to improve the quality of final image [11,17]. In some case, the amplitude of signals are also normalised in order to reduce noise in the final image due to variation in bonding interface or transducers performance $[14,16]$. The subtraction process is efficient in enhancing signal features arising from the presence of damage (including wave attenuation or reflection) and cancelling the wave reflections from the structure's free-edge that would otherwise cause artefacts in the final image $[25,26]$.

In the total focusing method, the structure is represented by a $2 \mathrm{D}$ image. For each pixel, the time taken by the waves to travel from the emitting transducer to that pixel and then to the receiving transducer is determined; this travel time is then used to extract the corresponding amplitude found in the signal collected with the same transducer pair. The summation of the amplitudes found for that pixel in each signal collected from each combination of transmitter and receiver defines the final pixel intensity. Ultimately this method relies on combining common features in the signals that are linked to the presence of the defect, the summation process leads to constructive interferences at the damage location in the reconstructed image and to destructive interferences for the noise. 


\begin{tabular}{|c|c|c|c|c|c|c|}
\hline Literature & $\begin{array}{l}\text { Signal processing } \\
\text { and/or TFM image } \\
\text { reconstruction } \\
\text { applied }\end{array}$ & $\begin{array}{l}\text { Inspected } \\
\text { structure }\end{array}$ & $\begin{array}{l}\text { Dominant } \\
\text { mode in } \\
\text { generated } \\
\text { signals }\end{array}$ & PZT No & Induced defects & $\begin{array}{l}\text { Location error } \\
\text { (based on } \\
\text { maximum } \\
\text { intensity location) }\end{array}$ \\
\hline $\begin{array}{l}\text { Michaels and } \\
\text { Michaels [16] }\end{array}$ & $\begin{array}{l}\text { - Input: residual } \\
\text { isignals } \\
\text { - Standard TFM } \\
\text { reconstruction } \\
\text { ' Fused multiple } \\
\text { TFM images } \\
\text { obtained with } \\
\text { multiple excitation } \\
\text { frequencies }\end{array}$ & $\begin{array}{l}\text { Aluminium } \\
\text { plate }\end{array}$ & $\begin{array}{l}\text { Multiple } \\
\text { modes (A0 } \\
\text { and S0) }\end{array}$ & 4 & $\begin{array}{l}\text { Hole } \varnothing 6.4 \mathrm{~mm} \\
\text { Hole } \varnothing 6.4 \mathrm{~mm} \\
\text { (located outside } \\
\text { the array) }\end{array}$ & $4.4 \mathrm{~mm}$ \\
\hline \multirow[t]{3}{*}{ Michaels [14] } & • Input: absolute & \multirow[t]{3}{*}{$\begin{array}{l}\text { Aluminium } \\
\text { plate }\end{array}$} & \multirow[t]{3}{*}{ S0 } & 6 & $\begin{array}{l}\text { Holes } \varnothing 2 \mathrm{~mm} \\
\text { Holes from } \varnothing 3 \\
\text { mm up to } \varnothing 6 \\
\text { mm }\end{array}$ & $\begin{array}{l}\text { Undetected } \\
\text { Within } 50 \mathrm{~mm} \\
\text { (based on visual } \\
\text { observation) }\end{array}$ \\
\hline & $\begin{array}{l}\text { Standard TFM } \\
\text { reconstruction }\end{array}$ & & & 5 and 6 & Holes $\varnothing 6 \mathrm{~mm}$ & $\begin{array}{l}\text { Within } 50 \mathrm{~mm} \\
\text { (based on visual } \\
\text { observation) }\end{array}$ \\
\hline & $\begin{array}{c}1 \\
1 \\
1 \\
1 \\
1 \\
1\end{array}$ & & & 6 & $\begin{array}{l}\text { Notch from } 3.2 \\
\text { mm long and up } \\
\text { to } 9.5 \mathrm{~mm}\end{array}$ & $\begin{array}{l}\text { Within } 50 \mathrm{~mm} \\
\text { (based on visual } \\
\text { observation) }\end{array}$ \\
\hline \multirow{2}{*}{$\begin{array}{c}\text { Sharif-Khodaei et al. } \\
{[11]}\end{array}$} & \multirow{2}{*}{$\begin{array}{l}\text { Same as Michaels } \\
(2008) \\
\vdots \\
\vdots \\
3\end{array}$} & $\begin{array}{l}\text { Flat CFRP } \\
\text { composite } \\
\text { plate }\end{array}$ & S0 & 4 & $\begin{array}{l}\text { Impact damage } \\
\text { of } 5.83 \mathrm{~J}\end{array}$ & $37 \mathrm{~mm}$ \\
\hline & & $\begin{array}{l}\text { Stiffened } \\
\text { CFRP } \\
\text { composite } \\
\text { panel }\end{array}$ & S0 & 4 & $\begin{array}{l}\text { Impact damage } \\
\text { of } 5.83 \mathrm{~J}\end{array}$ & $\begin{array}{l}\text { Within } 20 \mathrm{~mm} \\
\text { (based on visual } \\
\text { observation) }\end{array}$ \\
\hline \multirow{2}{*}{$\begin{array}{c}\text { Sharif-Khodaei et al. } \\
{[11]}\end{array}$} & \multirow{2}{*}{$\begin{array}{l}\text { Input: absolute } \\
\text { value of the residual } \\
\text { signal envelopes } \\
\text { Ireconstruction with } \\
\text { window function }\end{array}$} & $\begin{array}{l}\text { Flat CFRP } \\
\text { composite } \\
\text { plate }\end{array}$ & S0 & 4 & $\begin{array}{l}\text { Impact damage } \\
\text { of } 5.83 \mathrm{~J}\end{array}$ & $\begin{array}{l}\text { Within } 50 \mathrm{~mm} \\
\text { (based on visual } \\
\text { observation) }\end{array}$ \\
\hline & & $\begin{array}{l}\text { Stiffened } \\
\text { CFRP } \\
\text { composite } \\
\text { panel }\end{array}$ & S0 & 4 & $\begin{array}{l}\text { Impact damage } \\
\text { of } 5.83 \mathrm{~J}\end{array}$ & $\begin{array}{l}\text { Within } 20 \mathrm{~mm} \\
\text { (based on visual } \\
\text { observation) }\end{array}$ \\
\hline \multirow{3}{*}{$\begin{array}{c}\text { Salmanpour et al. } \\
{[18]}\end{array}$} & \multirow{3}{*}{$\begin{array}{l}\text { - Input: similar to } \\
\text { Michaels (2008) but } \\
\text { include a } \\
\text { temperature } \\
\text { icorrection factor } \\
\text { - Standard TFM } \\
\text { reconstruction (no } \\
\text { ipixel averaging) } \\
\text { ingel } \\
\end{array}$} & \multirow{3}{*}{$\begin{array}{l}\text { Flat CFRP } \\
\text { composite } \\
\text { plate }\end{array}$} & A0 & 5 & $\begin{array}{l}\text { Impact damage } \\
\text { of 5.68J (10 mm } \\
\text { in diameter } \\
\text { impactor head })\end{array}$ & $1.3 \mathrm{~mm}$ \\
\hline & & & A0 & 4 & $\begin{array}{l}\text { Impact damage } \\
\text { of } 5.68 \mathrm{~J}(10 \mathrm{~mm} \\
\text { in diameter } \\
\text { impactor head })\end{array}$ & $22.7 \mathrm{~mm}$ \\
\hline & & & SO & 4 & $\begin{array}{l}\text { Impact damage } \\
\text { of } 5.68 \mathrm{~J}(10 \mathrm{~mm} \\
\text { in diameter } \\
\text { impactor head })\end{array}$ & $13.7 \mathrm{~mm}$ \\
\hline
\end{tabular}

Table 1: Summary of experimental studies on the application of the TFM image reconstruction with guided wave signals for damage detection. 
In the case of data collected in a pitch and catch configuration with static sensor the presence of damage can cause wave reflection and attenuation, which leads to localised positive and localised negative amplitude in the residual signal waveforms [26]. However, most studies used the absolute value of the residual signals for the TFM image reconstruction process [11,14,27]. Although different defect types have been detected using TFM image reconstruction in metal [14,16,17] and in CFRP composite [11,28] structures, the ability of the system in accurately locating defects varies (as summarised in Table 1). This lack of consistency in location error is an issue for establishing confidently the reliability of the system.

\subsection{Image analysis using shape factors}

Although some image reconstruction techniques for guided wave data have been successful in detecting and locating damage in composites, there is less discussion in the current literature on how to analyse and quantify regions of interest in those images and relate to actual damage. In 2015, Zhang et al. [29] mentioned the lack of approved standards for defects classification and characterisation in ultrasonic array imaging. They proposed a defect classification method based on a feature extraction in echo dynamic curves and TFM images. The extracted features were compared with that found in a database of echo-dynamic curves (from the British Standard EN 5835) and simulated TFM images. However their research was limited to welded ferrous specimens and to data collected in pulse-echo configuration. Also, the method used for isolating the damaged regions was not detailed.

Defining a method for quantifying and classifying the shape and pattern of the damaged regions could contribute to interpreting the damage type with greater confidence as well as providing a means of comparing the performance of different imaging techniques. However, the main problem lies in defining the most adequate image characterisation technique to use. Shape analysis techniques could be a solution to that issue. They are applied in fields that require characterisation and differentiation between shapes. Examples of these fields include fish tracking [30] and identifying the presence of diseases with medical imaging [31,32]. Shape analysis involves the image segmentation to isolate specific regions of interest followed by the classification and characterisation of those regions using shape metrics (also referred as shape factors) [31,33,34]. A common segmentation method involves setting intensity thresholds, however, the image resolution and sample size can impact the final results [32]. The shape factors can be divided into different groups, this study will use global shape metrics, as defined by Khademi et al. [31]. It combines shape factors, such as circularity and eccentricity, which are based on intuitive quantities (such as area, perimeter) and used to quantify the shape geometry. Zhang et al. [34] highlighted that global shape metrics can have a limited efficiency when discriminating between close shapes or noisy image, which can lead to issues when developing an automated shape recognition system for a large database. Despite this, the benefit of using those global shape metrics in this study is that they provide a straightforward method of identifying geometrical similarities between the actual 
defects and the damaged regions in the reconstructed images. The most intuitive definition of the circularity factor is the ratio between defect perimeter squared and over its area [32,35]. The eccentricity factor corresponds to the ratio between major and minor axis of the ellipse that best fit the investigated region [30]. Although these factors are only determined for binary image (all pixels defining the shape have the same intensity) [31], the eccentricity can account of the intensity variation by calculating the best-fit ellipse as a function of the weighted centroid (which is equivalent to a centre of gravity where mass is replaced by pixel intensity) [30].

\section{Experimental set up}

\subsection{Data acquisition}

The inspected part was a $1 \mathrm{~m}^{2}(0 / 90 / \pm 45)$ quasi-isotropic layup CFRP laminate of $1 \mathrm{~mm}$ thickness (supplied by Easy Composites). A total of 16 PZT transducers were glued to the plate in a circular array, $400 \mathrm{~mm}$ in diameter, Figure 1. The PZT discs (supplied by PI ceramic) were $0.5 \mathrm{~mm}$ thick and had a diameter of $10 \mathrm{~mm}$. The transducers were connected to a PXI system (from NI) comprising a waveform generator, a multiplexer and a digitizer. The data were collected in pitch and catch configuration, where each PZT transducer was successively acting as either transmitter or receiver of waves, enabling the collection of 240 signals per inspection. The signal acquisition was performed in a laboratory at ambient temperature of approximately $22{ }^{\circ} \mathrm{C}$ (variations were estimated to be within the range of $\pm 2{ }^{\circ} \mathrm{C}$ ). 
(a)

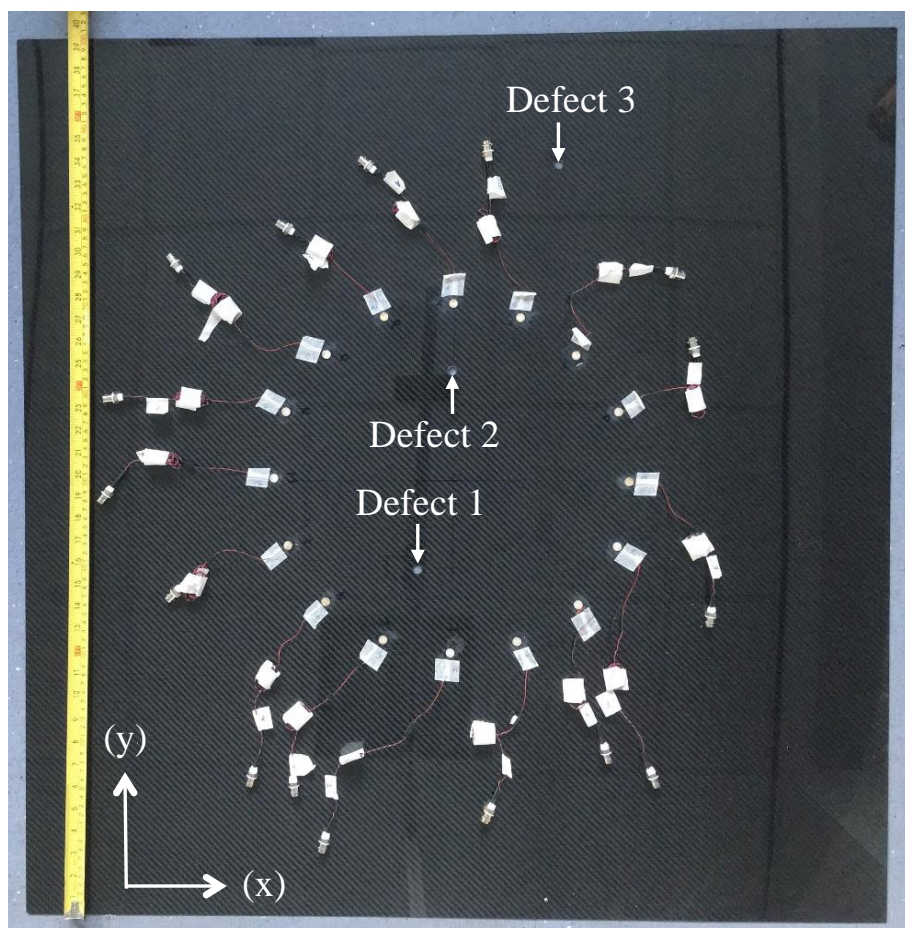

(b)

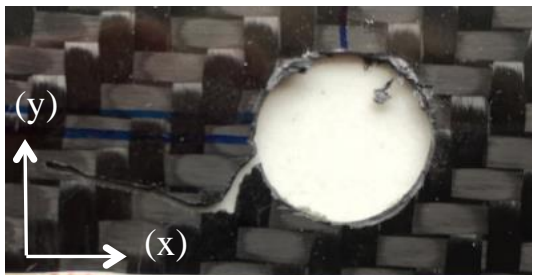

(c)

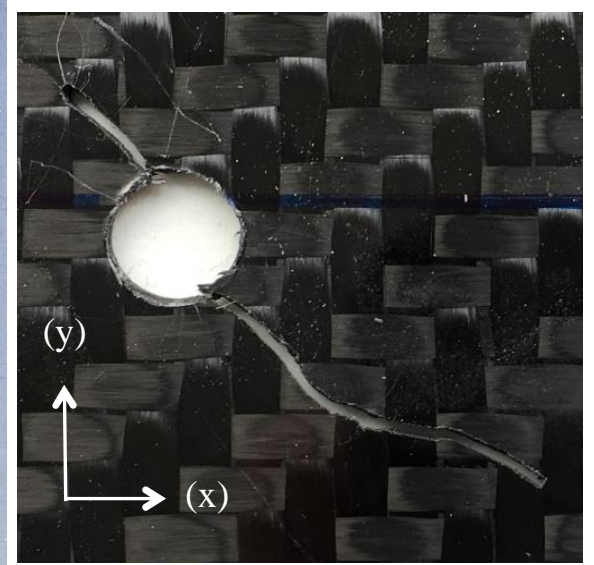

Figure 1: Pictures showing: (a) the CFRP composite plate with a circular array of 16 PZT and 3 induced defects; (b) defect 1(10 mm diameter hole with crack) between damage state 7 and up to 12; and (c) defect 2 (10mm diameter hole with crack) during damage state 11 and 12.

Excitation signals consisting of three-tone burst with a central frequency of $300 \mathrm{kHz}$ were sent to the transmitting transducer to generate the guided waves. At this frequency the generated signal was tuned on the fundamental symmetric mode (S0) that had an averaged wave speed of $4877 \mathrm{~m} . \mathrm{s}^{-1}$. The variation in wave speed due to direction is shown in Figure 2, where the standard deviation was $52.1 \mathrm{~m} \mathrm{~s}^{-1}$. Given that the standard deviation is relatively small the mean speed value was used for all calculations in this study. Based on the mean speed the S0 mode wavelength was approximately $16 \mathrm{~mm}$. In order to reduce the effect of random noise, each recorded signal was the result of an average of 1,000 successive collected signals with a sampling frequency of $100 \mathrm{MHz}$. The number of average was set high in order to minimize the noise as much as practically possible. The recording of 240 signals during each inspection of the plate lasted around 1 hour. Though previous studies performed on image reconstruction with guided waves used a significantly lower number of averaged signals (including 15 and 50 signals) [11,14]. 


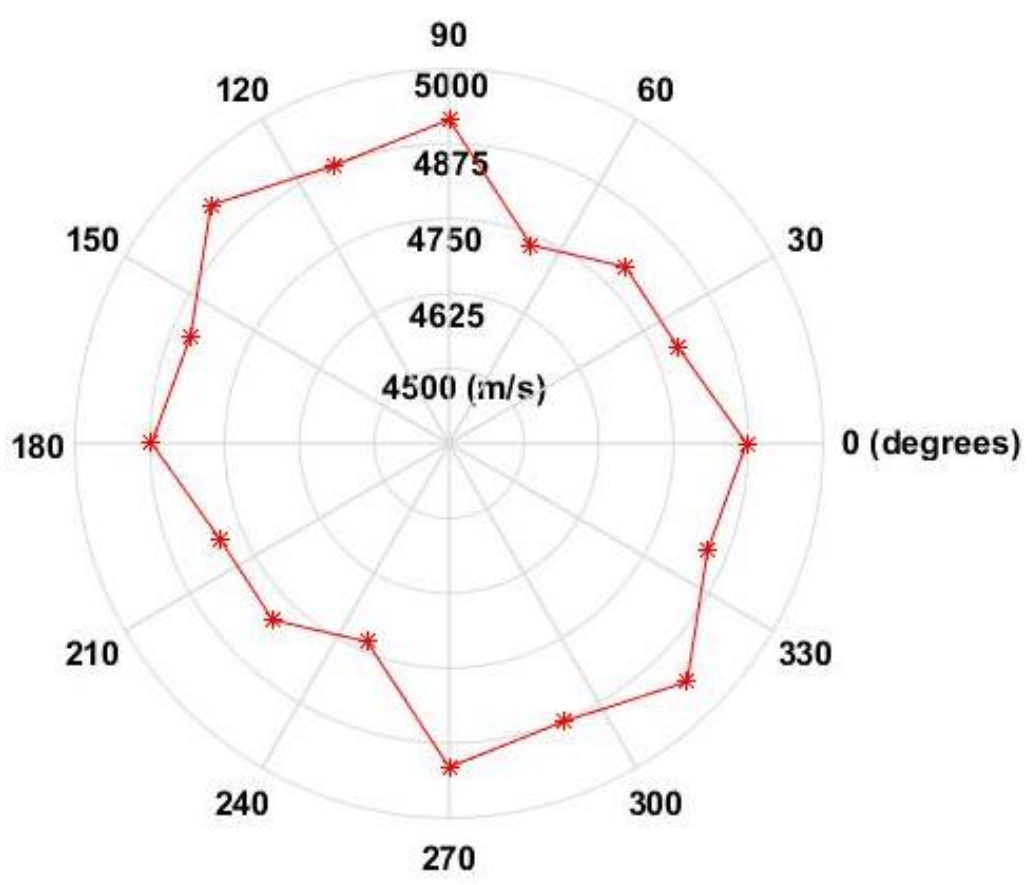

Figure 2: Polar velocity plot showing the variation in the wave speed in different directions. The speed was measured between transducer pairs placed opposite each other in the circular array. The distance between each pair was $400 \mathrm{~mm}$.

The first set of signals was collected before any damage was introduced in the structure and the plate was considered to be in a pristine condition; fabrication induced defects (voids, resin rich regions, fibre imperfections) are not considered but may exist. The data obtained from this first inspection constitute the initial baseline signals. This was followed by the progressive introduction of defects at three different locations (as shown in Figure 1) in the form of open holes of increasing size and cracks created by using a drill and a thin saw, respectively; the cracks were approximately $0.5 \mathrm{~mm}$ wide. The successive introduction and increasing size of defect 1 , defect 2 and defect 3 was divided into 12 damage states and guided wave inspection of the plate was performed for each state. The description of defect types and data collected is listed in Table 2. The Cartesian coordinates of the three introduced defects (based on the orthonormal coordinate system representing the full reconstructed image of the plate in the results section 4.1) were as follow:

- Defect $1(460,400) \pm 6 \mathrm{~mm}$;

- Defect $2(500,620) \pm 6 \mathrm{~mm}$;

- Defect $3(610,850) \pm 6 \mathrm{~mm}$.

It must be noted that these positions were measured using a ruler with $1 \mathrm{~mm}$ minimum graduation and height measurement were performed between the position of the centre of the plate and each defect location. The errors were estimated using the combined uncertainty (based on half the smallest graduation in analogue devices) and a coverage factor of 2 [36]. The drilling and sawing processes for introducing the defects could have induced additional errors. 


\begin{tabular}{|c|c|c|c|c|c|c|}
\hline & \multicolumn{2}{|l|}{ Defect 1} & \multicolumn{2}{|l|}{ Defect 2} & \multicolumn{2}{|c|}{ Defect 3} \\
\hline & Descritpion & $\begin{array}{l}\text { Area } \\
\left(\mathrm{mm}^{2}\right) \\
\end{array}$ & Descritpion & $\begin{array}{l}\text { Area } \\
\left(\mathrm{mm}^{2}\right)\end{array}$ & Descritpion & $\begin{array}{l}\text { Area } \\
\left(\mathrm{mm}^{2}\right) \\
\end{array}$ \\
\hline Pristine baseline & n.a. & n.a. & n.a. & n.a. & n.a. & n.a. \\
\hline Damage state \#1 & Hole $\varnothing 2 \mathrm{~mm}$ & 3 & n.a. & n.a. & n.a. & n.a. \\
\hline Damage state \#2 & Hole $\varnothing 2.5 \mathrm{~mm}$ & 5 & n.a. & n.a. & n.a. & n.a. \\
\hline Damage state \#3 & Hole $\varnothing 4 \mathrm{~mm}$ & 13 & n.a. & n.a. & n.a. & n.a. \\
\hline Damage state \#4 & Hole $\varnothing 5 \mathrm{~mm}$ & 20 & n.a. & n.a. & n.a. & n.a. \\
\hline Damage state \#5 & Hole $\varnothing 7 \mathrm{~mm}$ & 39 & n.a. & n.a. & n.a. & n.a. \\
\hline Damage state \#6 & Hole $\varnothing 10 \mathrm{~mm}$ & 79 & n.a. & n.a. & n.a. & n.a. \\
\hline Damage state \#7 & $\begin{array}{l}\text { Hole } \varnothing 10 \mathrm{~mm} \\
+ \text { crack } 11 \mathrm{~mm} \text { long }\end{array}$ & 84 & n.a. & n.a. & n.a. & n.a. \\
\hline Damage state \#8 & $\begin{array}{l}\text { Hole } \varnothing 10 \mathrm{~mm} \\
+ \text { crack } 11 \mathrm{~mm} \text { long }\end{array}$ & 84 & Hole $\varnothing 2 \mathrm{~mm}$ & 3 & n.a. & n.a. \\
\hline Damage state \#9 & $\begin{array}{l}\text { Hole } \varnothing 10 \mathrm{~mm} \\
+ \text { crack } 11 \mathrm{~mm} \text { long }\end{array}$ & 84 & $\begin{array}{l}\text { Hole } \varnothing 2 \mathrm{~mm} \\
+ \text { crack } 22 \mathrm{~mm} \text { long }\end{array}$ & 14 & n.a. & n.a. \\
\hline Damage state \#10 & $\begin{array}{l}\text { Hole } \varnothing 10 \mathrm{~mm} \\
+ \text { crack } 11 \mathrm{~mm} \text { long }\end{array}$ & 84 & $\begin{array}{l}\text { Hole } \varnothing 5 \mathrm{~mm} \\
+ \text { crack } 19 \mathrm{~mm} \text { long }\end{array}$ & 29 & n.a. & n.a. \\
\hline Damage state \#11 & $\begin{array}{l}\text { Hole } \varnothing 10 \mathrm{~mm} \\
+ \text { crack } 11 \mathrm{~mm} \text { long }\end{array}$ & 84 & $\begin{array}{l}\text { Hole } \varnothing 10 \mathrm{~mm} \\
+ \text { crack } 14 \mathrm{~mm} \text { long }\end{array}$ & 86 & n.a. & n.a. \\
\hline Damage state \#12 & $\begin{array}{l}\text { Hole } \varnothing 10 \mathrm{~mm} \\
+ \text { crack } 11 \mathrm{~mm} \text { long }\end{array}$ & 84 & $\begin{array}{l}\text { Hole } \varnothing 10 \mathrm{~mm} \\
+ \text { crack } 14 \mathrm{~mm} \text { long }\end{array}$ & 86 & Hole $\varnothing 10 \mathrm{~mm}$ & 79 \\
\hline
\end{tabular}

Table 2: List of defects present in the plate at each inspection of its damage state; the location of each defect in the plate is illustrated in figure 1.

\subsection{Signal processing and image reconstruction}

The total focusing method with full matrix capture image is the image reconstruction technique employed in this investigation. It uses as its main input data the subtraction between the envelope of the last collected signals and the envelope of the baseline signals. Additional input data includes the transducers position and averaged wave speed. The wave speed in the quasi-isotropic composite was assumed to be the same across the propagation plane and it was calculated based on the measured time of flight of the S0 mode for each collected signal. Preliminary data processing was required before performing the image reconstruction for each of the damage states listed in Table 2 . The preliminary processing is summarised by a flow chart in Figure 3. 


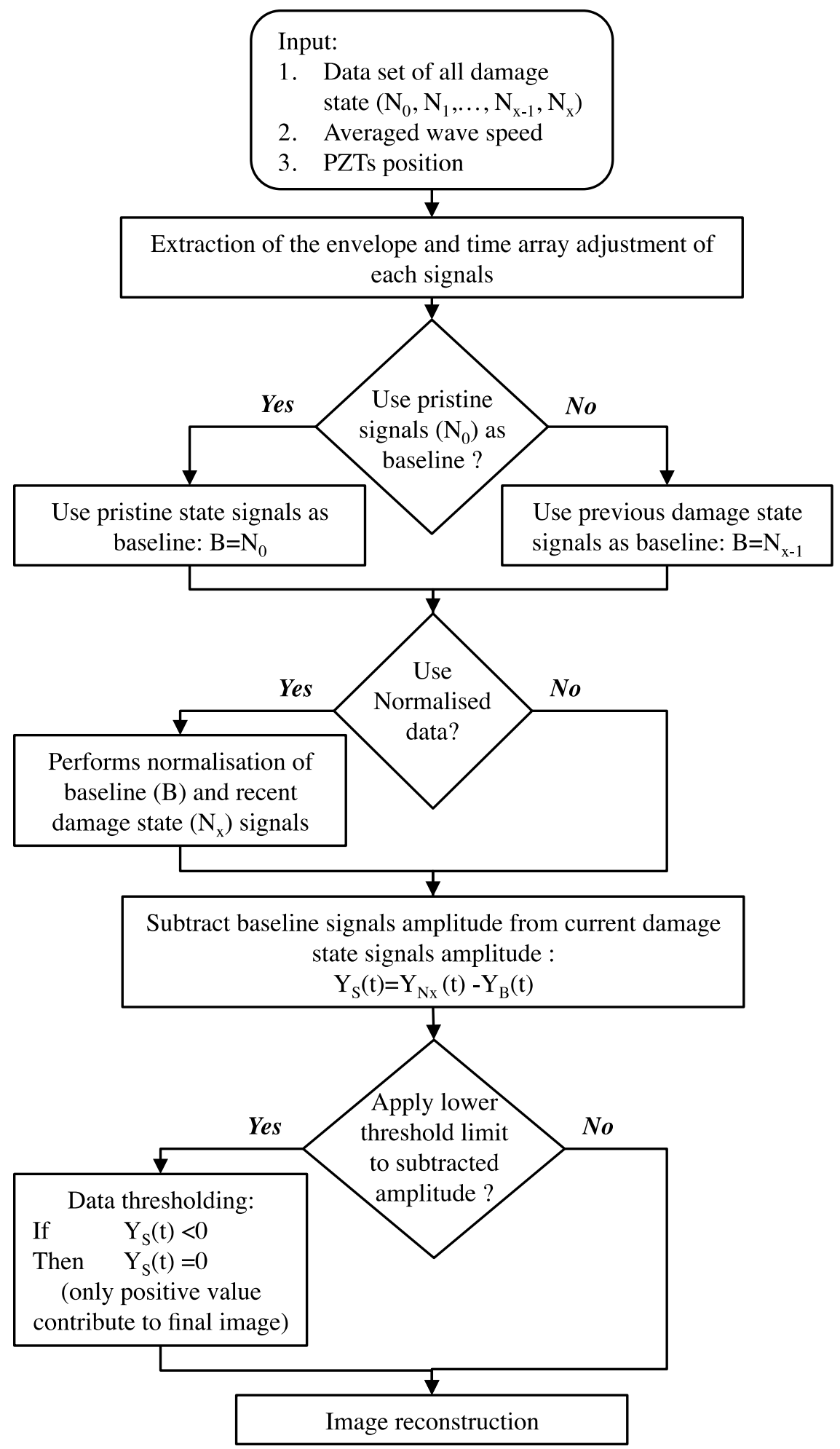

Figure 3: Flow chart summarising the preliminary signal processing, highlighting the eight different possible processing routes due to multiple choice. This includes the baseline selection, the activation of amplitude normalisation and thresholding.

A common step in the preliminary processing of each damage state data was extracting and smoothing the envelope of each signal using a Hilbert transform and a low pass filter. Then, the reference value in the time array of each collected signal was adjusted so that it coincides with the time at which the excitation signal was transmitted. In this study, the algorithm design allowed for 3 variations in the preliminary data processing. These variations where implemented in order to study 
which of the proposed data processing is most efficient in identifying damage. This resulted in 8 different output images obtained for each of the input damage states data described in Table 2

These variations are highlighted in the flowchart in Figure 3 by the three diamond frames, and they can be described by three processing parameters.

(i) Baseline selection parameter: Image reconstruction is either using the pristine data set (corresponding to the first data collected ' $\mathrm{N}_{0}$ ') or the previous data set as baseline. In other words, using the previous data set as baseline means that if an image is created using signals from the inspection number ' $\mathrm{N}_{\mathrm{x}}$ ' the baseline used is the set of signals corresponding to the inspection ' $\mathrm{N}_{\mathrm{x}-1}$ '. In this article the images obtained using ' $\mathrm{N}_{0}$ ' baseline data are referred as 'pristine baseline' while the images obtained using ' $\mathrm{N}_{\mathrm{x}-1}$ ' baseline data are labelled as 'previous baseline'.

(ii) Normalisation parameter: the image can be obtained either with or without normalised signals. The potential source of amplitude variations as observed in Figure 4 and their effect on the image reconstruction were described in section 2. The aim of this parameter is to remove those inconsistencies without removing the damping effect on amplitude. The normalisation was performed by finding the best fitting exponential decay trend to the distribution of the first peak amplitude of each pristine signal, Figure 5. The amplitude of each signal (of all the damage states data set including the pristine data) is then adjusted so that the amplitude of its first peak coincides with the fitted curve. An example of normalised signals is shown in Figure 6, where amplitude variation has been eliminated or dramatically reduced.

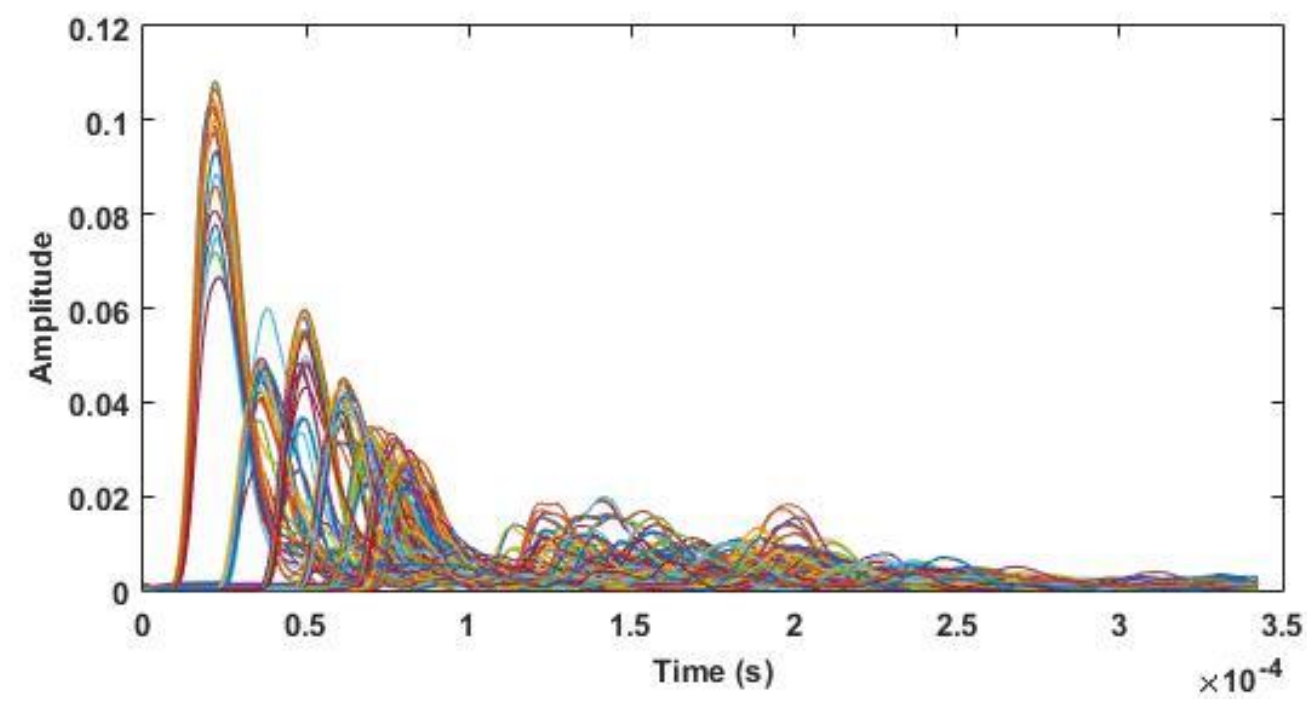

Figure 4: Signal envelopes of the 240 pristine signals collected with 16 PZT transducers in pitch and catch configuration. Disparities in the amplitude of signals collected at similar times can be observed. 


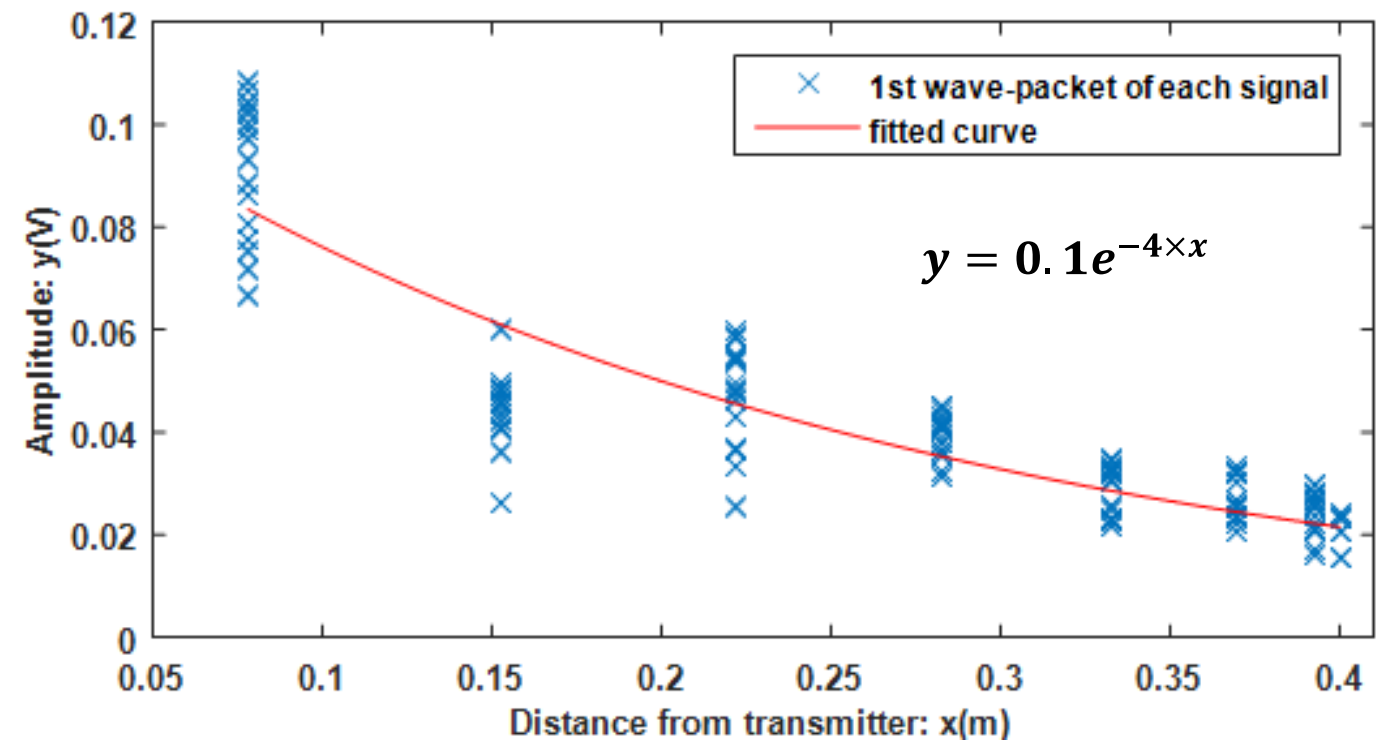

Figure 5: Bleu crosses represent the peak amplitudes (corresponding to S0 mode) extracted from the envelope of the 240 pristine signals (as shown in Figure 4) plotted against the distance between the emitting and the receiving transducers used to collect each signal. Inconsistency in the amplitude of signals collected with equally spaced transducers can be observed. This amplitude variation was compensated by adjusting the overall amplitude in the waveforms so that the peak amplitude of each signal coincided with that of the fitted curve.

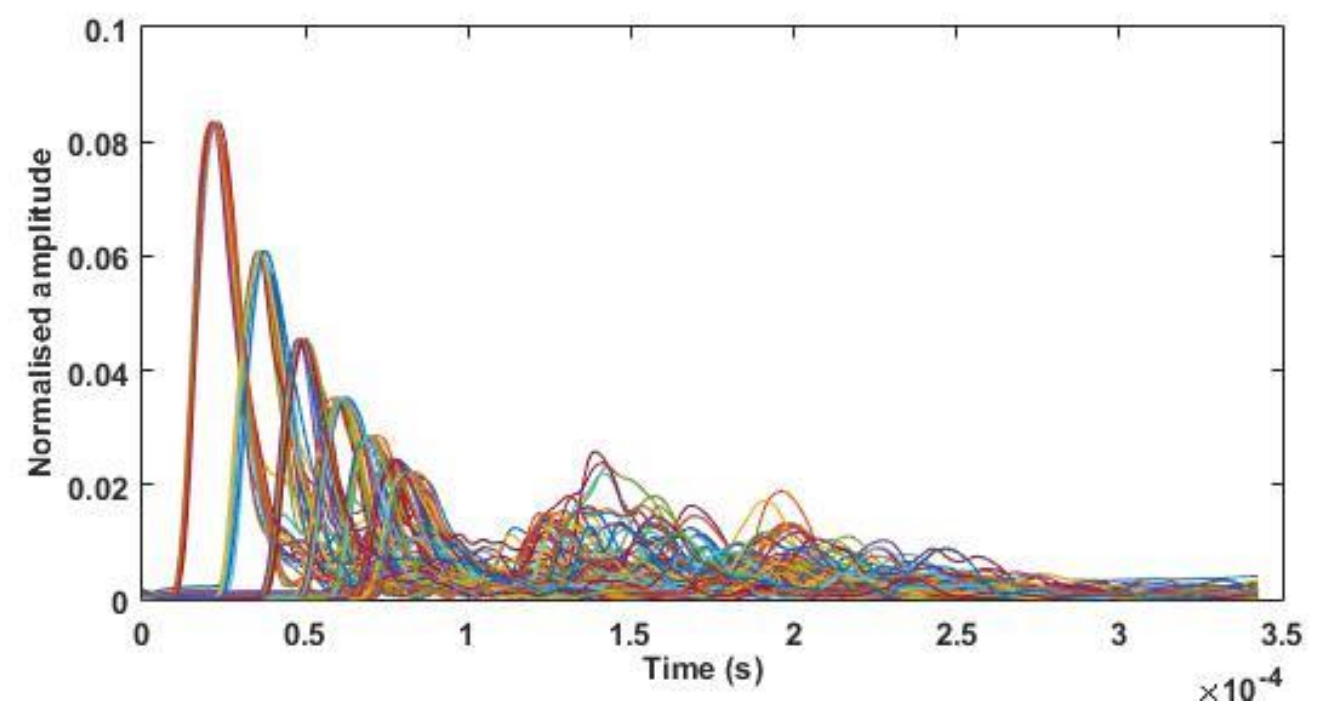

Figure 6: The 240 pristine signal envelopes after their amplitude was normalised based on the fitted curve shown in Figure 5.

(iii) Data thresholding parameter: consist in performing the image reconstruction by taking into account either all of the data range, or only the positive data from the subtraction (represented by $\mathrm{Y}_{\mathrm{s}}(\mathrm{x})$ in Figure 3) between the envelopes of the baseline and the damage state data. When a threshold was used it implies that data are segregated using a lower threshold limit at zero. In this case, the negative values on y-axis resulting from the signals subtraction were set to zero (also known as clipped-off) and therefore were excluded from the image reconstruction. 
After the preliminary signal processing, as shown in Figure 3, the image reconstruction was performed based on the Total Focusing Method with full matrix capture algorithm developed previously [17].

\section{Results and discussion}

\subsection{Identification of defect location in the reconstructed images of the CFRP plate}

In this section, images of the carbon fibre reinforced plastic plate at different damage states are reconstructed from the guided wave signals using the TFM with full matrix capture. The images shown in Figure 7 to Figure 13 have a linear resolution of 1 pixel per $\mathrm{cm}$ and they represent a 2D top-view of the whole plate. Each figure axis uses the same orthonormal coordinate system. Due to the large number of images generated only a few are shown here to illustrate results from the different processes. However, information from the images that are not displayed here is given in Table 3 and Table 4. These tables show the distance between the defect location coordinates and the maximum intensity pixel location coordinates found in each image. This metric was used to compare the image processing techniques studied (as previously described in section 3.2) and estimate their ability in detecting damage.

Results for all damage state images obtained with the different signal processing and image reconstruction methods used are presented in Table 3 and Table 4. It was established in the method section (section 3.1) how the defects were successively introduced in three different locations: defect 1 coordinates $(460,400) \pm 6 \mathrm{~mm}$, defect $2(500,620) \pm 6 \mathrm{~mm}$ and defect $3(610,850) \pm 6 \mathrm{~mm}$. Therefore the maximum intensity pixel was expected to be located in the vicinity of these positions. Since the introduced defects have different area size, the maximum intensity pixel might not be necessarily found in the centre of each defect but instead around its edge (especially in the case of the $10 \mathrm{~mm}$ diameter hole and $24 \mathrm{~mm}$ long crack). As a rule of thumb, the detection of a defect in an image was considered successful if the distance between the measured defect location and the location of the maximum intensity pixel was less or equal to $3 \mathrm{~cm}$ (equivalent to 3 pixels). 
Distance between defect location and maximum intensity pixel location found for each DS (Damage State)

\begin{tabular}{|c|c|c|c|c|c|c|c|c|c|}
\hline Image processed: & DS 1 & DS 2 & DS 3 & DS 4 & DS 5 & DS 6 & DS 7 & Mean & $\begin{array}{l}\text { Standard } \\
\text { Deviation }\end{array}$ \\
\hline $\begin{array}{l}\text { Using the pristine signals as baseline; } \\
\text { Without the signals being normalised; } \\
\text { Using a lower limit threshold. }\end{array}$ & 2.0 & 1.0 & 0.0 & 1.4 & 1.4 & 1.4 & 1.4 & 1.2 & 0.6 \\
\hline $\begin{array}{l}\text { Using the pristine signals as baseline; } \\
\text { Without the signals being normalised; } \\
\text { Without using a lower limit threshold. }\end{array}$ & 30.8 & 30.8 & 30.4 & 21.4 & 21.3 & 30.4 & 36.0 & 28.7 & 5.0 \\
\hline $\begin{array}{l}\text { Using the pristine signals as baseline; } \\
\text { With the signals being normalised; } \\
\text { Using a lower limit threshold. }\end{array}$ & 1.0 & 1.0 & 1.0 & 1.0 & 1.4 & 1.4 & 1.4 & 1.2 & 0.2 \\
\hline $\begin{array}{l}\text { Using the pristine signals as baseline; } \\
\text { With the signals being normalised; } \\
\text { Without using a lower limit threshold. }\end{array}$ & 30.8 & 30.8 & 15.8 & 15.8 & 36.0 & 36.2 & 36.0 & 28.8 & 8.5 \\
\hline $\begin{array}{l}\text { Using the previous damage state signals as baseline; } \\
\text { Without the signals being normalised; } \\
\text { Using a lower limit threshold. }\end{array}$ & n.a & 1.0 & 1.4 & 1.4 & 1.0 & 0.0 & 2.2 & 1.0 & 0.7 \\
\hline $\begin{array}{l}\text { Using the previous damage state signals as baseline; } \\
\text { Without the signals being normalised; } \\
\text { Without using a lower limit threshold. }\end{array}$ & n.a & 22.8 & 23.4 & 24.1 & 26.1 & 23.8 & 32.4 & 21.8 & 3.3 \\
\hline $\begin{array}{l}\text { Using the previous damage state signals as baseline; } \\
\text { With the signals being normalised; } \\
\text { Using a lower limit threshold. }\end{array}$ & n.a & 1.0 & 1.4 & 1.4 & 1.0 & 0.0 & 2.2 & 1.0 & 0.7 \\
\hline $\begin{array}{l}\text { Using the previous damage state signals as baseline; } \\
\text { With the signals being normalised; } \\
\text { Without using a lower limit threshold. }\end{array}$ & n.a & 33.3 & 24.8 & 16.3 & 26.1 & 23.8 & 14.0 & 19.7 & 6.4 \\
\hline
\end{tabular}

Table 3: Distance (cm) between the location of defect 1 and the centre of maximum intensity pixel found in all reconstructed images with linear resolution of $1 \mathrm{~cm}$ per pixel. Distances were calculated based on the Cartesians coordinates and distances shorter than $3 \mathrm{~cm}$ are highlighted in green. All listed damage states contain a single defect location. The description of the different damage states can be found in Table 2. Additional details on the different image reconstruction processing used are given in section 3.2 and Figure 3. 
Distance between defect location and maximum intensity pixel location found for each DS (Damage State)

\begin{tabular}{|c|c|c|c|c|c|c|c|c|c|c|}
\hline Image processing: & DS 8 & & DS 9 & & DS 10 & & DS 11 & & DS 12 & \\
\hline $\begin{array}{l}\text { Using the pristine signals as baseline; } \\
\text { Without the signals being normalised; } \\
\text { Using a lower limit threshold. }\end{array}$ & 1.4 & Defect: 1 & 0.0 & Defect: 2 & 0.0 & Defect: 2 & 0.0 & Defect: 2 & 1.0 & Defect: 2 \\
\hline $\begin{array}{l}\text { Using the pristine signals as baseline; } \\
\text { Without the signals being normalised; } \\
\text { Without using a lower limit threshold. }\end{array}$ & 36.0 & Defect: 1 & 33.5 & Defect: 2 & 20.6 & Defect: 2 & 21.3 & Defect: 2 & 20.5 & Defect: 2 \\
\hline $\begin{array}{l}\text { Using the pristine signals as baseline; } \\
\text { With the signals being normalised; } \\
\text { Using a lower limit threshold. }\end{array}$ & 1.4 & Defect: 1 & 0.0 & Defect: 2 & 0.0 & Defect: 2 & 0.0 & Defect: 2 & 0.0 & Defect: 2 \\
\hline $\begin{array}{l}\text { Using the pristine signals as baseline; } \\
\text { With the signals being normalised; } \\
\text { Without using a lower limit threshold. }\end{array}$ & 14.9 & Defect: 1 & 14.9 & Defect: 1 & 20.6 & Defect: 2 & 20.5 & Defect: 2 & 20.5 & Defect: 2 \\
\hline $\begin{array}{l}\text { Using the previous damage state signals as baseline; } \\
\text { Without the signals being normalised; } \\
\text { Using a lower limit threshold. }\end{array}$ & 1.0 & Defect: 2 & 0.0 & Defect: 2 & 1.4 & Defect: 2 & 0.0 & Defect: 2 & 0.0 & Defect: 3 \\
\hline $\begin{array}{l}\text { Using the previous damage state signals as baseline; } \\
\text { Without the signals being normalised; } \\
\text { Without using a lower limit threshold. }\end{array}$ & 7.2 & Defect: 1 & 18.6 & Defect: 2 & 13.6 & Defect: 2 & 21.9 & Defect: 2 & 4.1 & Defect: 3 \\
\hline $\begin{array}{l}\text { Using the previous damage state signals as baseline; } \\
\text { With the signals being normalised; } \\
\text { Using a lower limit threshold. }\end{array}$ & 1.0 & Defect: 2 & 0.0 & Defect: 2 & 1.4 & Defect: 2 & 0.0 & Defect: 2 & 0.0 & Defect: 3 \\
\hline $\begin{array}{l}\text { Using the previous damage state signals as baseline; } \\
\text { With the signals being normalised; } \\
\text { Without using a lower limit threshold. }\end{array}$ & 4.5 & Defect: 1 & 33.5 & Defect: 2 & 17.8 & Defect: 2 & 22.6 & Defect: 2 & 3.2 & Defect: 3 \\
\hline
\end{tabular}

Table 4: Distance (cm) between the locations of closest defects and the centre of the maximum intensity pixel found in all reconstructed images with linear resolution of $1 \mathrm{~cm}$ per pixel. The defect closest to the maximum intensity pixel is indicated on the right inside of each calculated distance. Notes damage states 8 to 11 contains two defects location, and damage state 12 contains a third defects outside the array of transducers. Distances were calculated based on the Cartesians coordinates and distances shorter than $3 \mathrm{~cm}$ are highlighted in green. Description of the different damage states can be found in Table 2. Additional details on the different image reconstruction processing used are given in section 3.2 and Figure 3.

The images representing damage state 1 (containing a $2 \mathrm{~mm}$ diameter hole defect) are shown in Figure 7. Each image was obtained using a different variation of signal processing and image reconstruction methods. They were all obtained using the amplitude subtraction of the pristine baseline signals from the signals collected after the first defect (a hole of $2 \mathrm{~mm}$ diameter) was introduced. The presence of defect 1 cannot be observed in images shown in Figure 7a and Figure 7b, while it can be observed in Figure 7c Figure 7d, as highlighted by the highest intensity region in the images; the black square represents the actual damage location. The main difference between those two groups is that a lower threshold limit (keeping only the positive amplitude) was used in the processing of Figure $7 \mathrm{c}$ Figure $7 \mathrm{~d}$. The use of a threshold implies that the negative values were excluded from the image reconstruction. In contrary, no threshold was used and all subtracted data were retained in the reconstruction of Figure $7 \mathrm{a}$ and Figure $7 \mathrm{~b}$. This observation is consistent with quantitative result found in Table 3 and Table 4 showing that for all damage state images that where processed without using a lower limit threshold could not identify defect locations. Another observation is that apart from the value of the maximum intensity no significant difference is 
observed at this resolution between images that were processed using the normalised signals (such as Figure $7 \mathrm{~b}$ and Figure $7 \mathrm{~d}$ ) and those that were not (such as Figure 7a Figure 7c). Also, their corresponding calculated distances from the defect locations shown in Table 3 and Table 4 for every damage state studied are the same. The effect of normalisation is further investigated for higher resolution images in the next section.

(a)

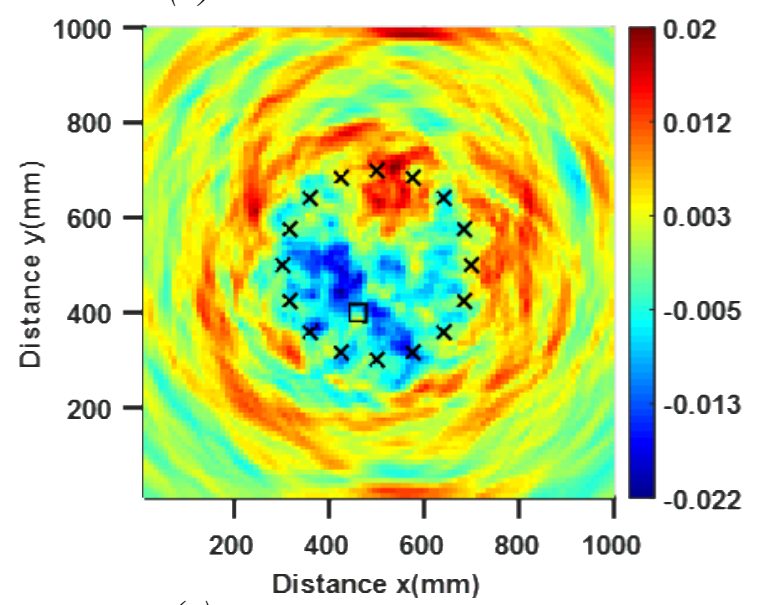

(c)

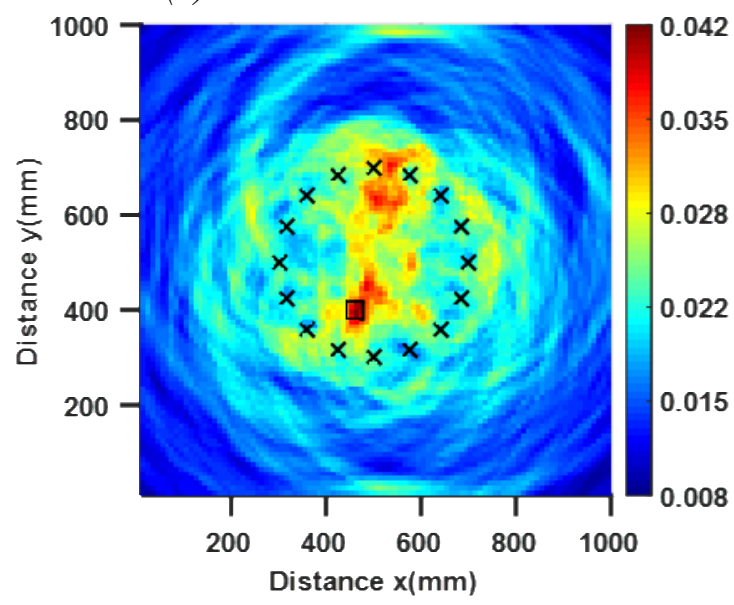

(b)

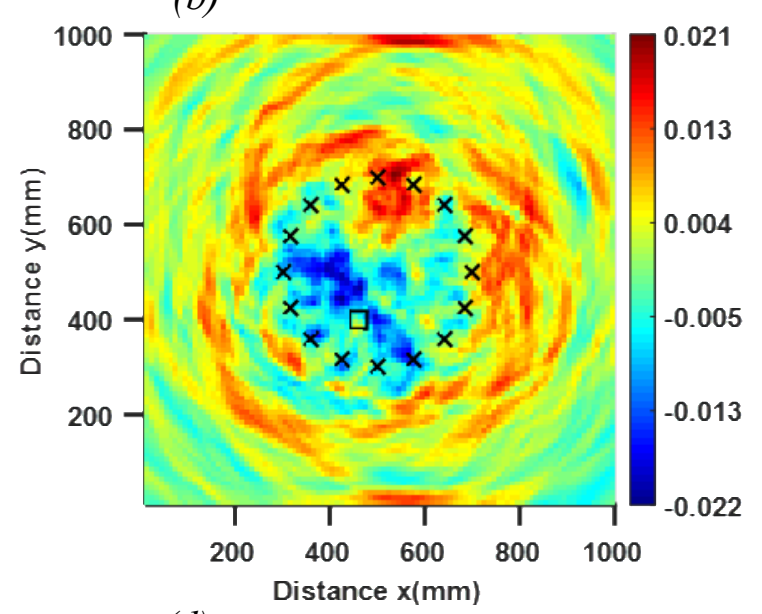

(d)

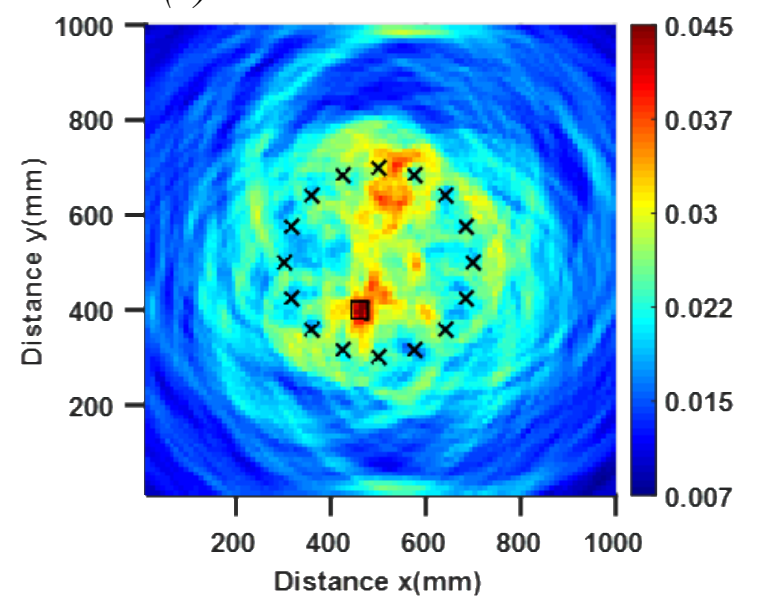

Figure 7: Images of damage state 1 (2mm hole), processed using the pristine signals as baseline and: (a) without using a lower limit threshold and without the signals being normalised; (b) without using a lower limit threshold but with the signals being normalised; (c) with using a lower limit threshold (only positive amplitude are processed) but without the signals being normalised; (d) with a lower limit threshold and with the signals being normalised. The black crosses describe the position of the transducers, and the black square corresponds to the damage location.

The significant impact that applying a lower limit threshold has on the ability to detect defects can also be observed in Figure 8 and Figure 9. These figures are both representing damage state 6 that consists of a single $10 \mathrm{~mm}$ hole. However, unlike images in Figure 7 and Figure 8 that were processed using the pristine baseline, images in Figure 9 where processed using the previous acquired signals as baseline (in this case corresponding to damage state 5). Although not all images of all damage states are shown here, Table 3 and Table 4 confirm that images processed without using the lower limit threshold at zero can not detect and locate the defects. These findings suggest that applying a lower threshold limit at zero to the subtracted amplitude signals, hence performing the image reconstruction only using values equal or greater than zero, is the most significant 
processing parameter that is enabling the identification of defects in the CFRP plate investigated. A possible explanation to this lies in the different way damage can affect guided wave signals. As stated in the background section, guided wave modes can be attenuated by and reflected from a defect leading to the presence of local minima and maxima, respectively, in the amplitude of the signal waveform after baseline subtraction. Images in Figure 7a, Figure 7b, Figure 8a and Figure 9a display a low intensity region close to the expected defect location. This suggests that signal features caused by waves being attenuated by the defect have a preponderant effect on the reconstructed image when compared to features linked to wave reflection from the defect. In other words, the ranges of local amplitude loss tend to be greater than that of local amplitude gain in the signal waveforms. This is a potential consequence of the higher wave damping properties of carbon fibre reinforced plastic composites when compared to isotropic materials such as aluminium [5]. When the intensity of pixels close to the damage is being determined, the effect of wave attenuation and wave reflection on signal waveforms has a conflicting contribution in the amplitude summation process of the TFM. This prevents the creation of constructive interferences, which are the key element in the TFM that enables identifying defects. Nevertheless, images in Figure 7c, Figure 7d, Figure $8 \mathrm{~b}$ and Figure $9 \mathrm{~b}$ show that segregating data can be a solution to this issue. Segregating positive and negative amplitudes (for instance by using a threshold) in the image reconstruction amounts to distinguishing between types of information provided by local gain and loss in the signal's waveform.

(a)

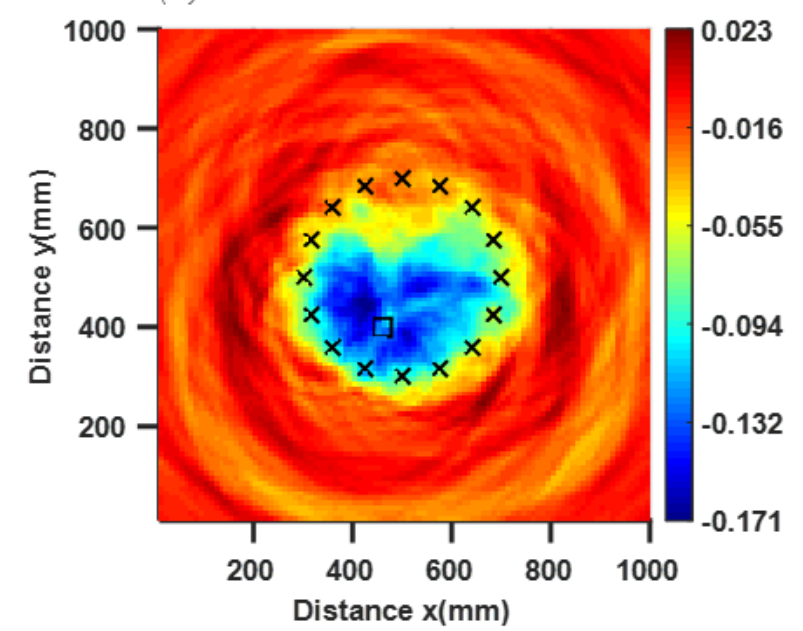

(b)

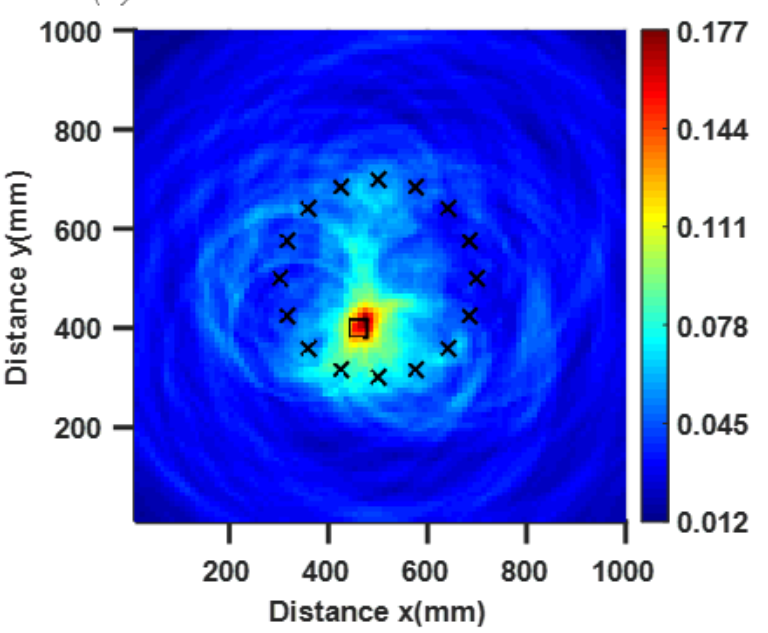

Figure 8: Images of damage state $6(10 \mathrm{~mm}$ hole), processed using the pristine signals as baseline and: (a) without using a lower limit threshold and without the signals being normalised; (b) with using a lower limit threshold (only positive amplitudes are processed) but without the signals being normalised. The black crosses describe the positions of the transducers, and the black square corresponds to the damage location. 
(a)

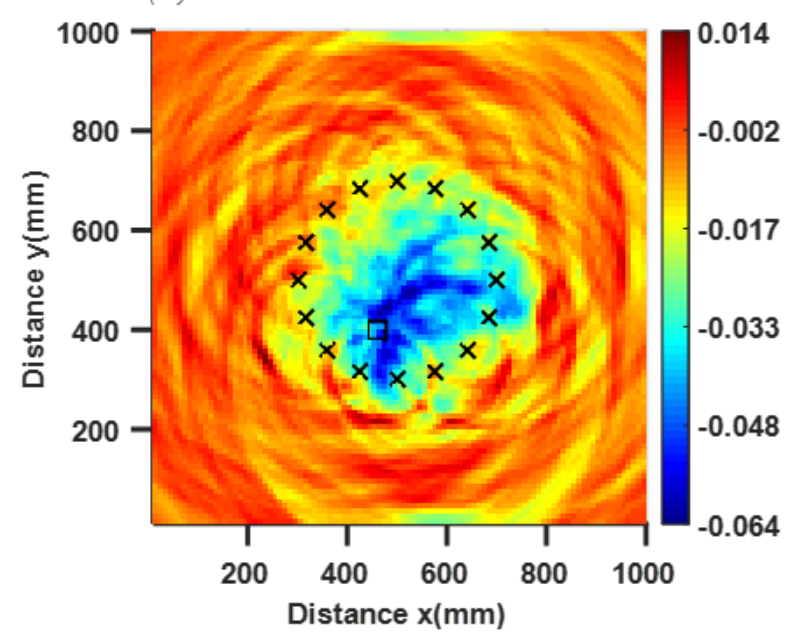

(b)

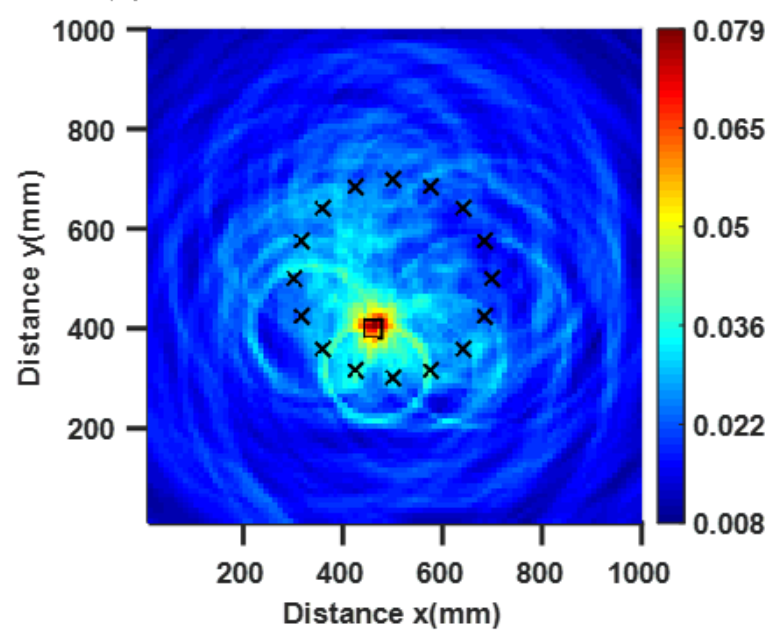

Figure 9: Images of damage state $6(10 \mathrm{~mm}$ hole), processed using the previous damage state signals as baseline and: (a) without using a lower limit threshold and without the signals being normalised; (b) with using a lower limit threshold (only positive amplitudes are processed) but without the signals being normalised. The black crosses describe the positions of the transducers, and the black square corresponds to the damage location.

Images shown in Figure 10 to Figure 13 were all processed using the lower threshold limit; hence they were reconstructed only using the positive amplitude from the subtracted signals. In these figures images (a) were processed using the pristine baseline, while images (b) were processed using signals from the previous damage state as baseline. In addition, Figure 14 shows the value of the pixel with the maximum intensity found in the images representative of each damage state and obtained using all the processing methods involving the use of a lower limit threshold (meaning only positive and zero data where processed) including those using normalised signals. Figure 10a and Figure 10b representing damage state 7, which consists of a single hole and a crack, show that both types of baseline used in the image reconstruction enabled the detection of the defect.
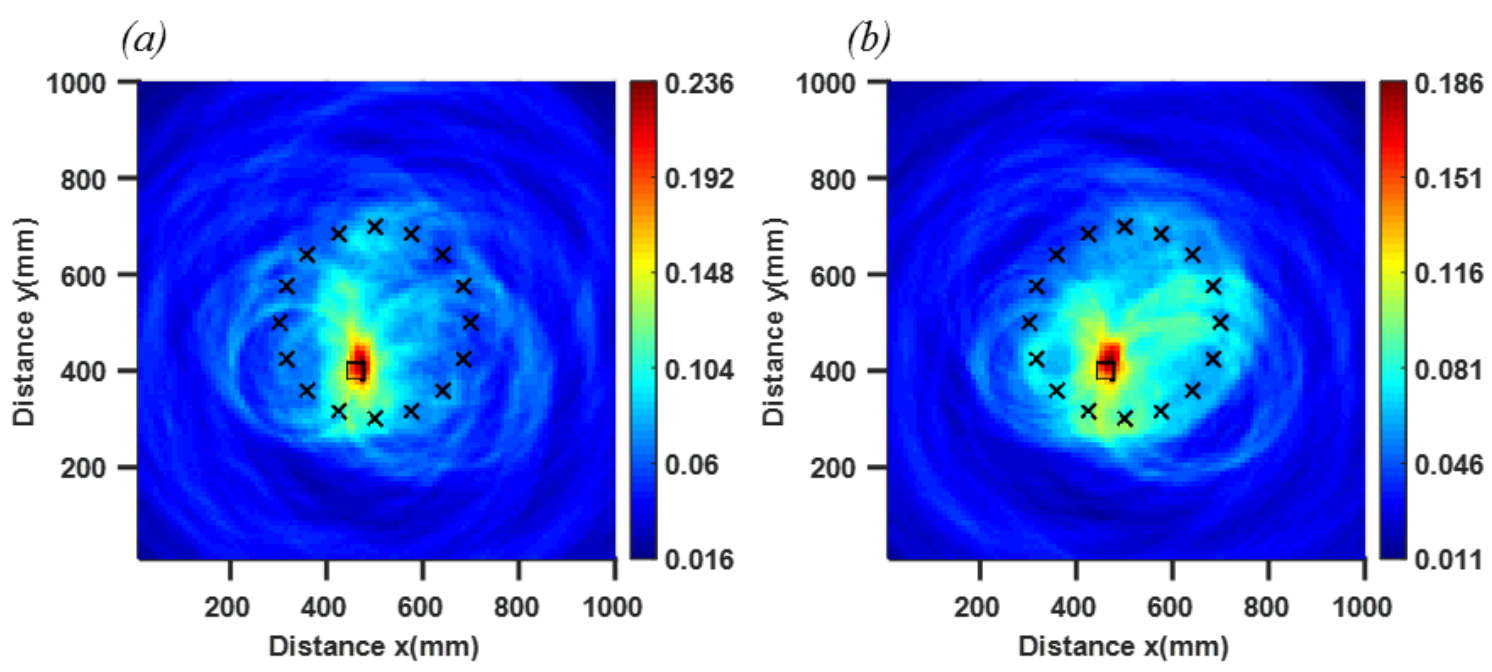

Figure 10: Images of damage state 7 (consisting of $10 \mathrm{~mm}$ diameter hole with an $11 \mathrm{~mm}$ long crack), processed using a lower limit threshold (excluding negative amplitude) and using: (a) 
pristine signals as baseline without the signals being normalised; (b) previous damage state signals as baseline without the signals being normalised.

Images representative of the plate under damage state 8 are shown in Figure 11. At damage state 8 the CFRP plate contains two defects, defect 1 is a $10 \mathrm{~mm}$ diameter hole with a $11 \mathrm{~mm}$ crack and defect 2 is a $2 \mathrm{~mm}$ diameter hole. In this case the image processed using the pristine baseline signals (Figure 11a) cannot detect the presence of the additional defect, the $2 \mathrm{~mm}$ hole. The new defect can only be detected and located in Figure $11 \mathrm{~b}$ where the image was processed using the previous damage state signals as baseline. Still, in Figure $11 \mathrm{~b}$ a large region of high intensities can be seen around the location of defect 1 . This region could be the result of artefacts or, although unlikely, the $11 \mathrm{~mm}$ crack at the hole edge, defect 1; further analysis is required

(a)

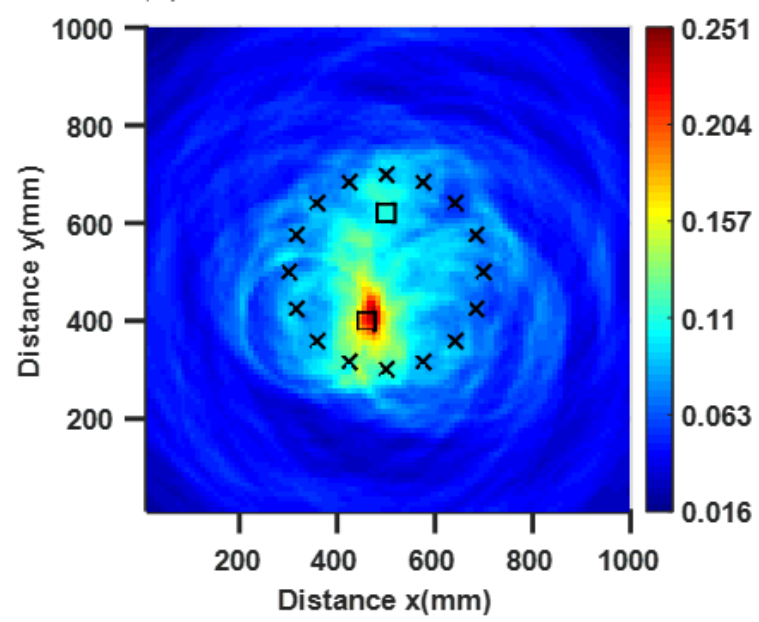

(b)

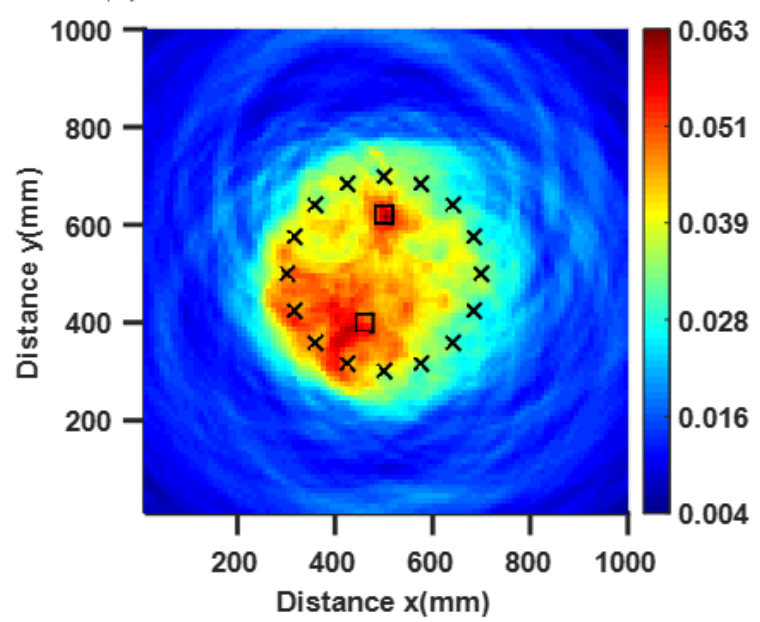

Figure 11: Images of damage state 8 (consisting of two defect locations a $10 \mathrm{~mm}$ diameter hole with $11 \mathrm{~mm}$ long crack and a $2 \mathrm{~mm}$ diameter hole), processed using a lower limit threshold (excluding negative amplitude) and using: (a) pristine signals as baseline without the signals being normalised; (b) previous damage state signals as baseline without the signals being normalised. The black crosses describe the positions of the transducers, and the black square corresponds to the damage location.

In contrary to observation in Figure 11a, Figure 12a show that it is possible to identify the presence of multiple defects in TFM images reconstructed using the pristine baseline. However, the pixels characterising defect 1 (10 $\mathrm{mm}$ hole with an $11 \mathrm{~mm}$ long crack) have a lower overall intensity than the pixels characterising defect 2 (consisting of a $24 \mathrm{~mm}$ long crack). Image in Figure $12 \mathrm{~b}$ only shows the presence of the most recently introduced defect (defect 2). This was expected since the subtraction of the baseline signals, consisting of data collected at damage state 8 , from the current signals collected at damage state 9 removed the traces of defect 1 . 
(a)

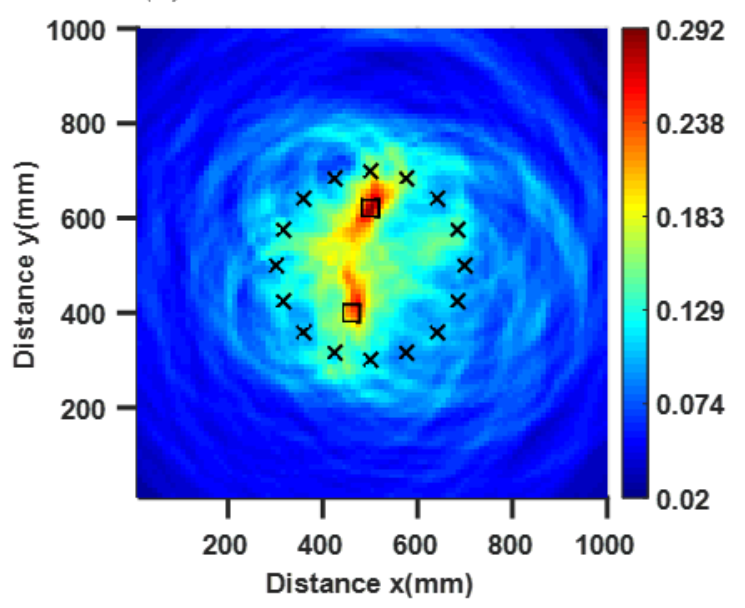

(b)

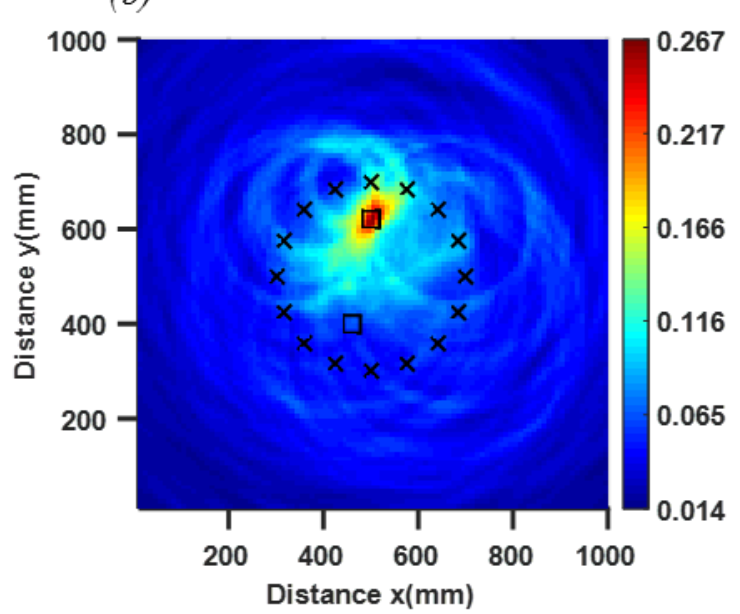

Figure 12: Images of damage state 9 (consisting of two defect locations a $10 \mathrm{~mm}$ diameter hole with $11 \mathrm{~mm}$ long crack and a $2 \mathrm{~mm}$ diameter hole with a $24 \mathrm{~mm}$ long crack), processed using a lower limit threshold (excluding negative amplitude) and using: (a) pristine signals as baseline without the signals being normalised; (b) previous damage state signals as baseline without the signals being normalised. The black crosses describe the positions of the transducers, and the black square corresponds to the damage location.

Images in Figure 13 were obtained using signals collected after a third defect (hole with a $10 \mathrm{~mm}$ diameter) was introduced outside the circular array of transducers (corresponding to damage state 12 in Table 2). The image shown in Figure 13a, that was processed using the pristine signal as baseline, failed to identify the presence of the newly introduced defect 3. However, the image in Figure $13 \mathrm{~b}$ processed using the previous damage state (damage state 11) as baseline, was successfully captured. Figure 14 shows the maximum intensity value obtained for all images processed using a lower limit threshold. The comparison between the maximum intensity of images in Figure $13 \mathrm{~b}$ and Figure $9 \mathrm{~b}$ for instance show that the intensity generated by the presence of defect 3 (a new $10 \mathrm{~mm}$ diameter hole) is similar to that generated by a smaller increase in defect size (located at defect 1) in damage state 6 (corresponding to an increased hole diameter of $3 \mathrm{~mm}$ compared to the previous damage state). A possible explanation is that the location of the third defect outside the array means that some of the reflected waves had to travel longer distance resulting in lower amplitude in some acquired signals. As a result, the significantly higher intensity of the pixels representing defect 1 and defect 2 might have overwhelmed the system ability to see defect 3 in Figure 13a. 
(a)

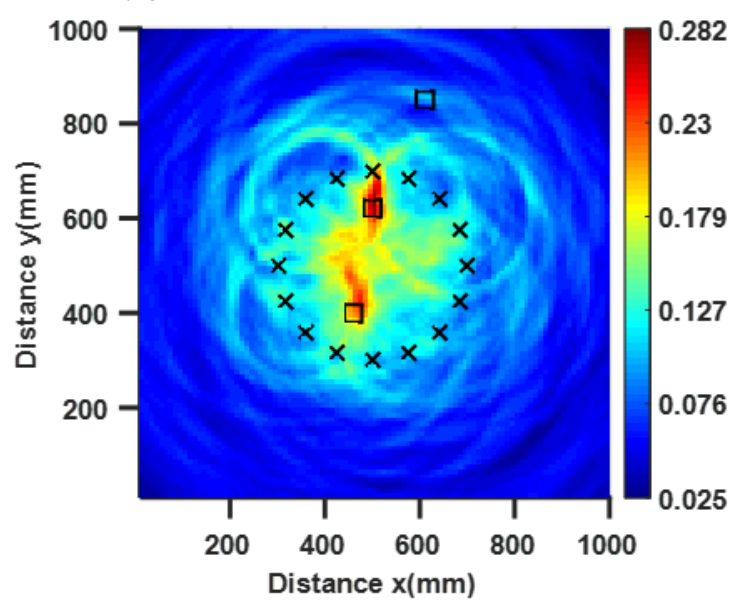

(b)

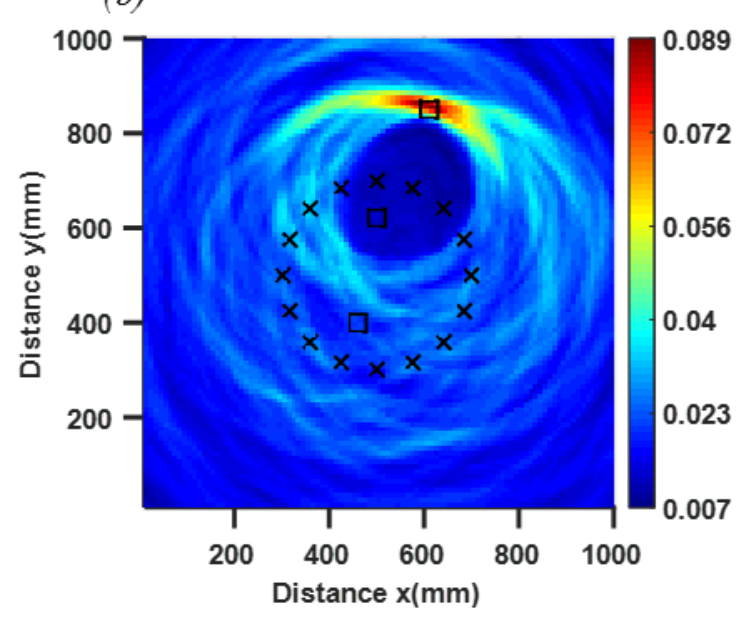

Figure 13: Images of damage state 12 (consisting of three defects location with the third defect a 10 $\mathrm{mm}$ diameter hole situated outside the array of sensors), processed using a lower limit threshold (excluding negative amplitude) and using: (a) pristine signals as baseline without the signals being normalised; (b) previous damage state signals as baseline without the signals being normalised. The black crosses describe the positions of the transducers, and the black square corresponds to damage location.

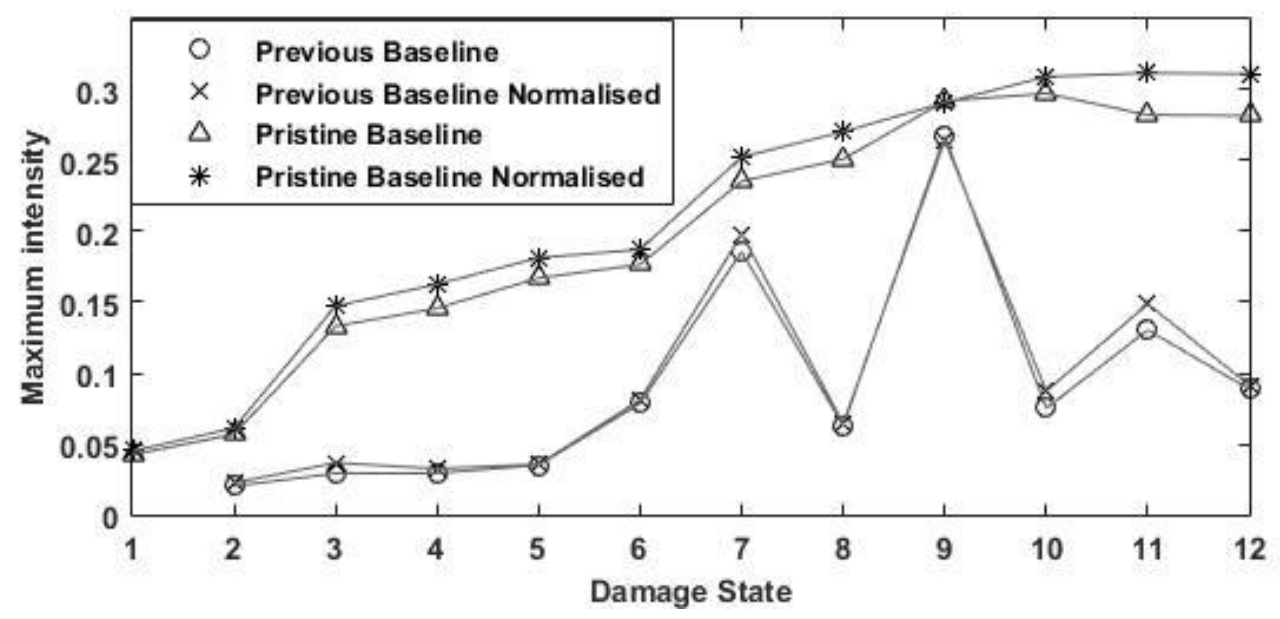

Figure 14: Graph showing the maximum intensity value found for each damage state; images obtained using only the positive value (lower limit threshold implemented) and the following processing parameter variations: the pristine or the previous collected data as baseline; the signals normalised or not.

Over the twelve damage states investigated, there are two instances where images reconstructed using the pristine baseline (and a lower limit threshold) could not identify the presence of a newly introduced damage. This occurred for images representing damage state 8, Figure 11a and damage state 12 as shown in Figure 13a. In addition, the results in Table 4 show that in most cases the images containing multiple defects and processed using the pristine baseline (and a lower limit threshold) have their maximum intensity pixel closer to the newly introduced defect, except for images representing damage state 8 and damage state 12 . In contrary, results in Table 4 suggest that images processed using the previous damage state as baseline (and a lower limit threshold) systematically identify the presence and location of the most recently introduced damage. 
They also enabled the measurement of the intensity variation caused by each newly added damage as graphically shown in Figure 14. Ultimately, images processed using signals acquired from the previous damage state as a baseline (and of a lower limit threshold), were found to be the most reliable and sensitive to each new defect introduced in the plate. Still only images processed using the pristine baseline (and a lower limit threshold) can in some case make the presence of multiple defects visible in the same image. Finally, it should be noted that at the low resolution of the images presented in this section, it is difficult to estimate defect size, or identify defect type, i.e., it is hard to separate an open hole from a long crack.

\subsection{Analysis of defect shape and type in the reconstructed images}

Although the ability of each processing method to locate the damage was established, their ability to inform on the defect shape and type is yet to be defined. It is expected that images processed using the previous damage state signal as baseline will not be as successful in describing the defect type as those using the pristine baseline; since those images do not show the full damage state but rather its evolution. Distinguishing between the damage types based on the reconstructed images requires analysing the shape drawn by the group of pixels that constitute the damaged regions. Therefore, classifying defect types required first the segmentation of the damaged region by setting an intensity threshold, followed by a comparison between the different patterns using specific shape features and shape factors. In this study, two shape factors, circularity and eccentricity, were used in an attempt to classify the defect type. In addition, the areas of the defect shapes were compared with the estimated area of each induced defect (as described in Table 2). In order to improve the analysis of each defect pattern, zoomed images such as shown in Figure 15 were processed using a higher linear resolution of $1 \mathrm{~mm}$ per pixel and focusing on smaller area $\left(10,000 \mathrm{~mm}^{2}\right)$ of the plate covering the damaged regions. Though, it must be noted that this resolution might not represent well the contour of the smallest defect (such as a $2 \mathrm{~mm}$ hole) as well as that of larger defects. 

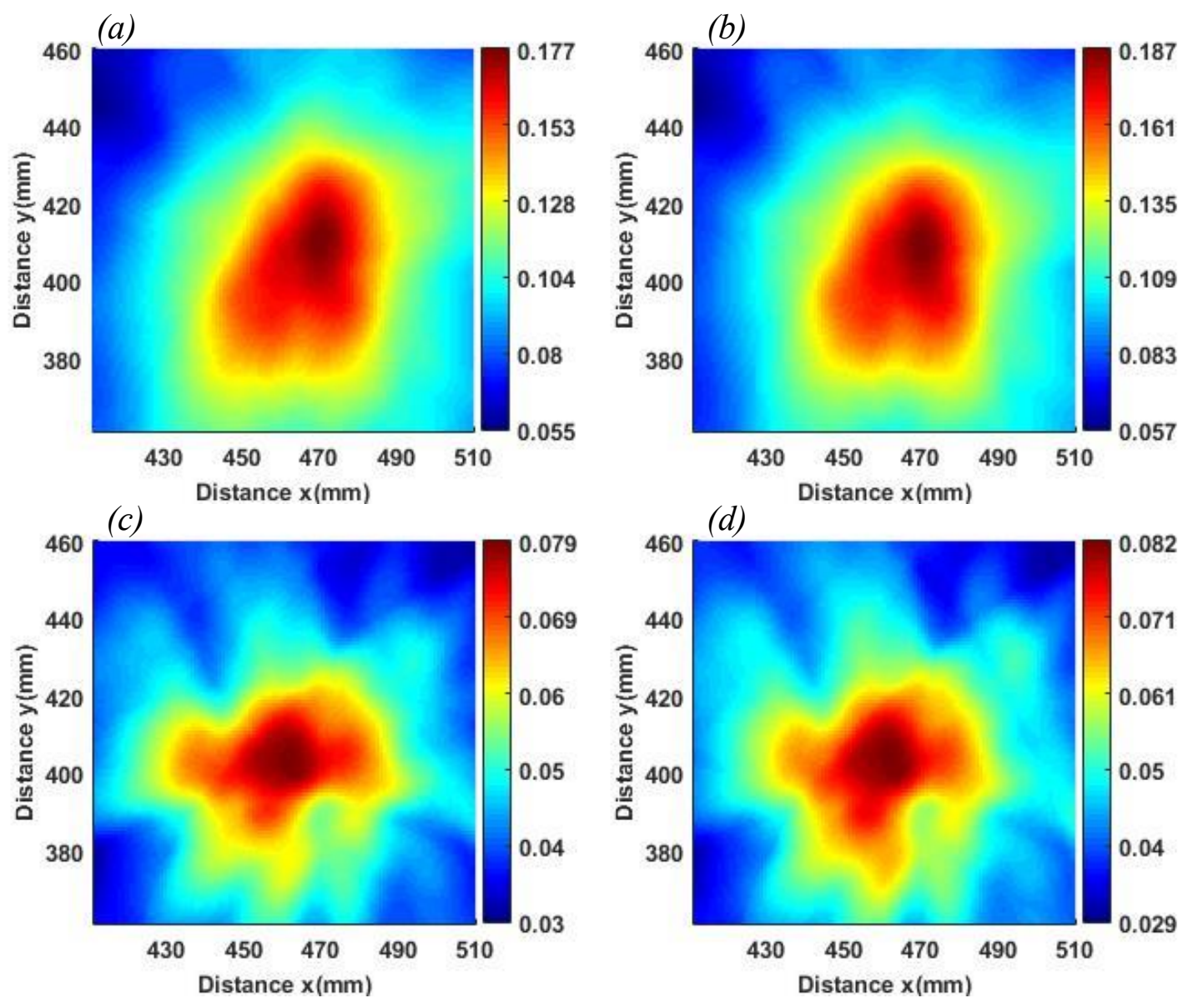

Figure 15: Zoomed images on defect 1 of damage state 6 (10 $\mathrm{mm}$ hole), processed using a lower limit threshold (excluding negative amplitude) and using: (a) pristine signals as baseline without the signals being normalised; (b) pristine signals as baseline with the signals being normalised; (c) previous damage state signals as baseline without the signals being normalised; (d) previous damage state.

Images zoomed on the damage regions were obtained for all damage states employing all four image reconstruction methods described, using a lower limit threshold (and only used the positive amplitude) in their processing. They also correspond to the four image reconstruction methods that gave the best identification of defect location as seen in Table 3. Examples of zoom images are shown in Figure 15. In case of multiple defects the zoom was performed in the region of the defect that was closest to the maximum intensity pixel (based on results shown in Table 4). The defect shape factors were determined based on these images and the results are plotted in Figure 16 to Figure 18. Note that no shape factor was obtained for damage state 8 in Figure 16a, Figure 16b, Figure 17a, Figure 17b Figure 18a and Figure 18b since for images processed using the pristine baseline defect 2 could not be identified. In each zoom image the shape factors were determined for pattern originated from different segmentation with thresholds ranging from $80 \%$ to $96 \%$ of the maximum intensity. The aim was to identify the evolution of the shape factors with segmentation thresholds and select one that was the most appropriate in classifying the defect type. The four graphs in each figure represent the resulting shape factors obtained for images reconstructed using different data processing, as described in section 3.2: Figure 16a and Figure 17a represent shape factors measured from zoom images that were processed using the pristine data as baseline and 
without normalising the signals (like image shown in Figure 15a). Figure $16 \mathrm{~b}$ and Figure $17 \mathrm{~b}$ represent shape factors measured from images processed using the pristine baseline and using the signal normalisation (Figure 15b). Figure 16c represents shape factors measured from images processed using the previous baseline signals as baseline and without normalising the signals (Figure 15c). Figure 16d represent shape factors measured from images processed using the previous baseline signals as baseline and using the signal normalisation (like image shown in Figure $15 \mathrm{~d})$.

\subsubsection{Circularity factor}

The circularity factor, as shown in Figure 16, represents how close a shape is to a circle (or disc)[35]. In this study $\mathrm{C}_{f}$ was defined as the ratio between the area of the shape $\left(\mathrm{A}_{\text {shape }}\right)$ divided by the area of a circle $\left(\mathrm{A}_{\text {eq }}\right)$ with equal perimeter $\left(\mathrm{P}_{\text {shape }}\right)$ to that shape given by Equation 1, and taken values between 0 and 1 .

$C_{f}=\frac{\mathrm{A}_{\text {shape }}}{\mathrm{A}_{\mathrm{eq}}}=\frac{4 \pi \mathrm{A}_{\text {shape }}}{\mathrm{P}_{\text {shape }}{ }^{2}}$

The closer to 1 the circularity factor is the more the shape resembles a disc. Since $\mathrm{C}_{f}$ is a function of the shape perimeter, it is also sensitive to the roughness (irregularity) of the shape contour. The shape perimeter was determined based on the outer centre-to-centre pixel approach as described by Dunkelberger and Mitchell [37]. It was expected that images containing open hole defects (such as described in damage state 1 to 6, Figure 3) would have greater circularity factor than images containing a through-thickness crack defect (such as described in damage state 7, 9, 10 and 11, Figure 3). Graphs in Figure 16a and Figure 16b show that for each damage state, most of the percentage thresholds used to segment the defect shape lead to similar circularity factor values. An exception to this can be observed when the segmentation threshold is $96 \%$, which is probably too high for this resolution, with not enough remaining pixels to describe the defect shape. The drop in circularity factor values observed for damage state 7 , which corresponds to the presence of the first crack, seems to confirm that the image of circular hole type of defect display a higher $\mathrm{C}_{f}$ value than that found for image of crack-type defect. An exception is found for damage state 1, which has a defect consisting of a $2 \mathrm{~mm}$ circular hole and has a circular factor value similar to that found for images of crack-type defects. It must be noted that the difference between the circularity factor value of holes and cracks is more apparent on the graph representing images processed using the normalised signals (Figure 16b compared to Figure 16a). Finally, as expected, the circularity factors obtained for images processed using the previous damage state as baseline, shown in Figure 16c and Figure 16d, are inconclusive regarding the classification of defect type. 
(a)

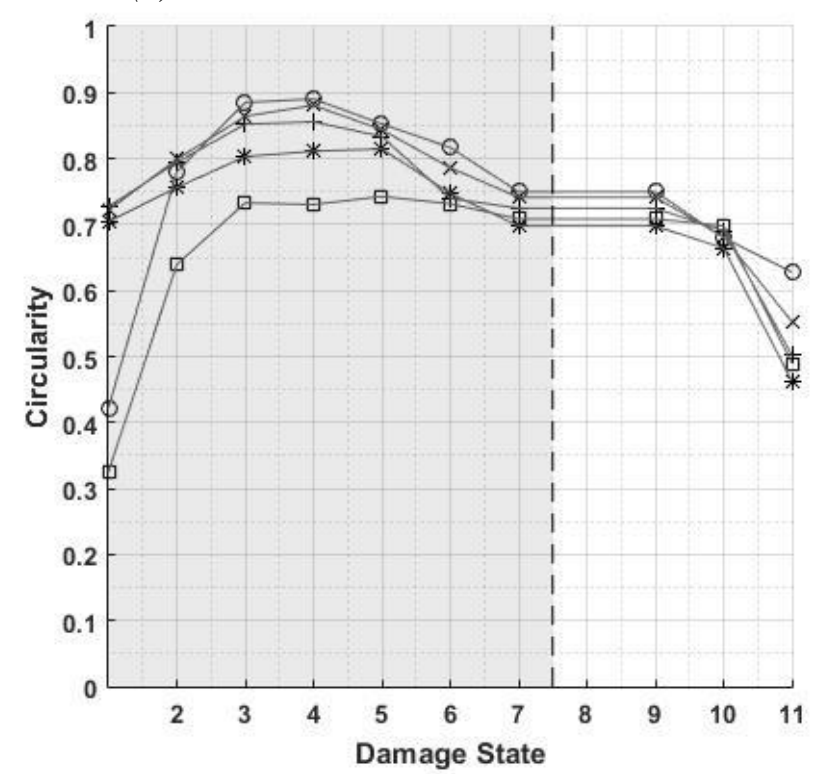

(c)

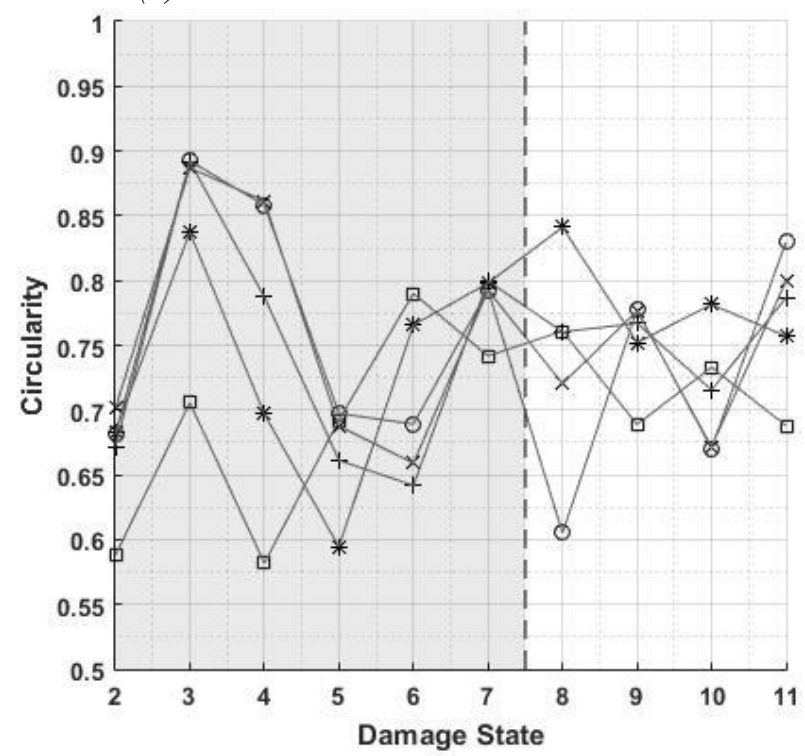

(b)

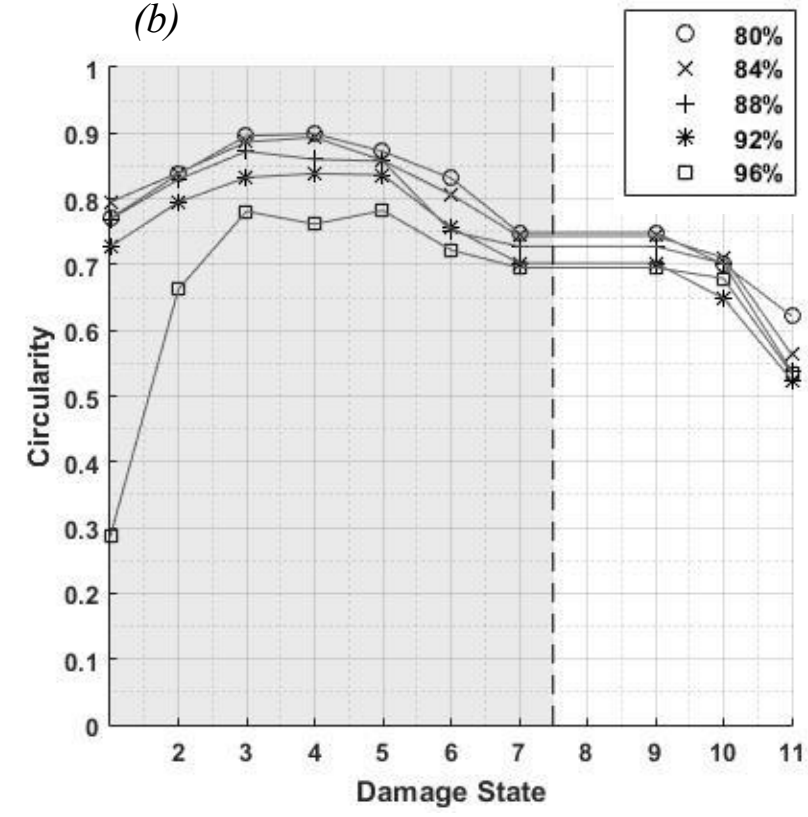

(d)

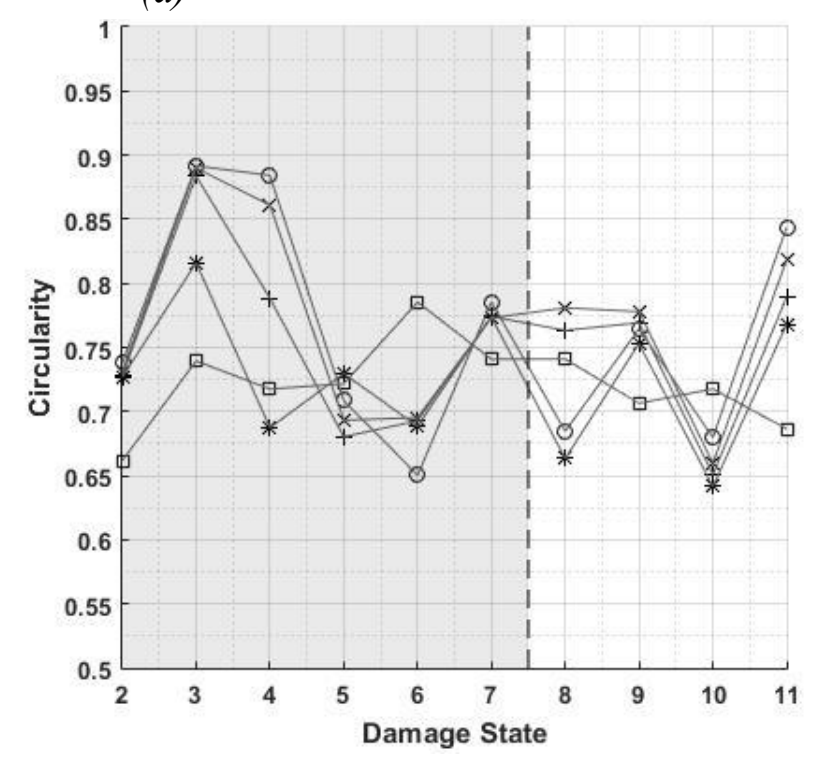

Figure 16: Circularity factor for different segmentation threshold values of images obtained by processing: (a) pristine signals as baseline; (b) pristine signals as baseline with the signals being normalised; (c) previous damage state signals as baseline; (d) previous damage state signals as baseline with the signals being normalised. The grey region corresponds to data related defect 1 and the white region corresponds to data related to defect 2. In the case of both graphs (a) and (b) at damage state 8, defect 2 was not detected.

\subsubsection{Eccentricity factor}

The eccentricity factor, $e_{f}$, shown in Figure 17, represents how elongated a shape is. It is based on the ratio of the minor over the major axis of an ellipse that best fits the defect shape. The eccentricity factor, $e_{f}$, values can range between 0 and 1 . When $e_{f}$ is equal to 1 the ellipse that best fits the shape has its minor and major axis equal, in that case the ellipse is a circle. The closer $e_{f}$ is to 0 the more the best fit ellipse has a major axis length longer than its minor axis length; meaning that the smaller is $e_{f}$ the more the studied shape is elongated. Unlike the circularity factor, the eccentricity factor $e_{f}$ is not sensitive to the shape contour or irregularity. The ellipse and its axes 
were determined using the MATLAB function developed by Candelier et al., [30], which determines the best ellipse fit of a shape based on its weighted centroid (calculated using the weighted average of the pixel intensities that form the shape). The trend followed by the eccentric factor values in Figure 17a and in Figure 17b, is similar to that found for the circularity factors in Figure 16a and Figure 16b. All segmentation thresholds lead to a similar trend between the shape factors. Images representing large single hole defect (above $4 \mathrm{~mm}$ in diameter) have a higher $e_{f}$ value than images representing hole with cracks defect. However images representing small diameter holes (such as that of damage state 1 and 2) display eccentricity factor similar to that of images representing cracks.

(a)

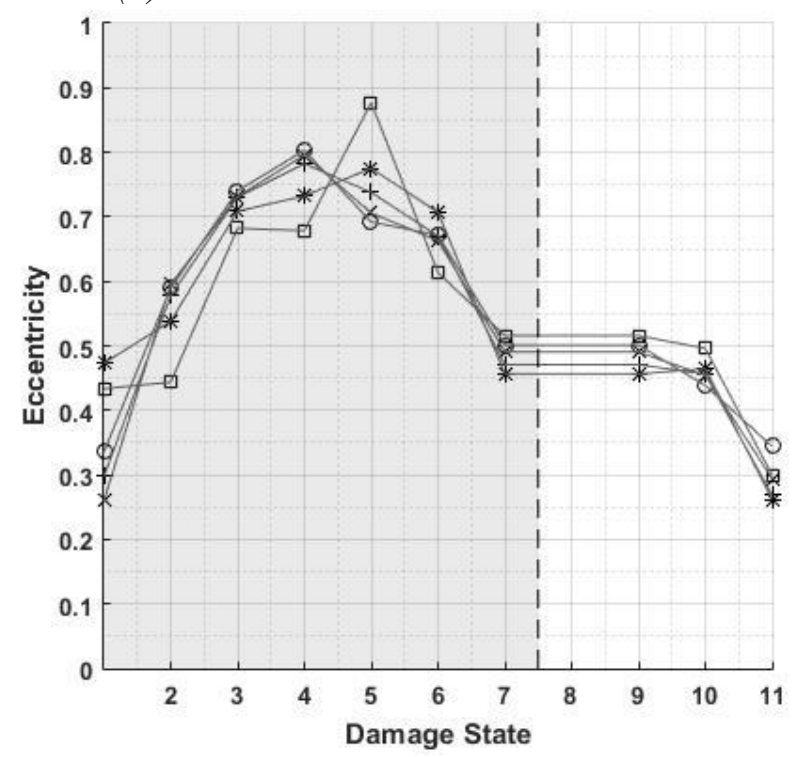

(b)

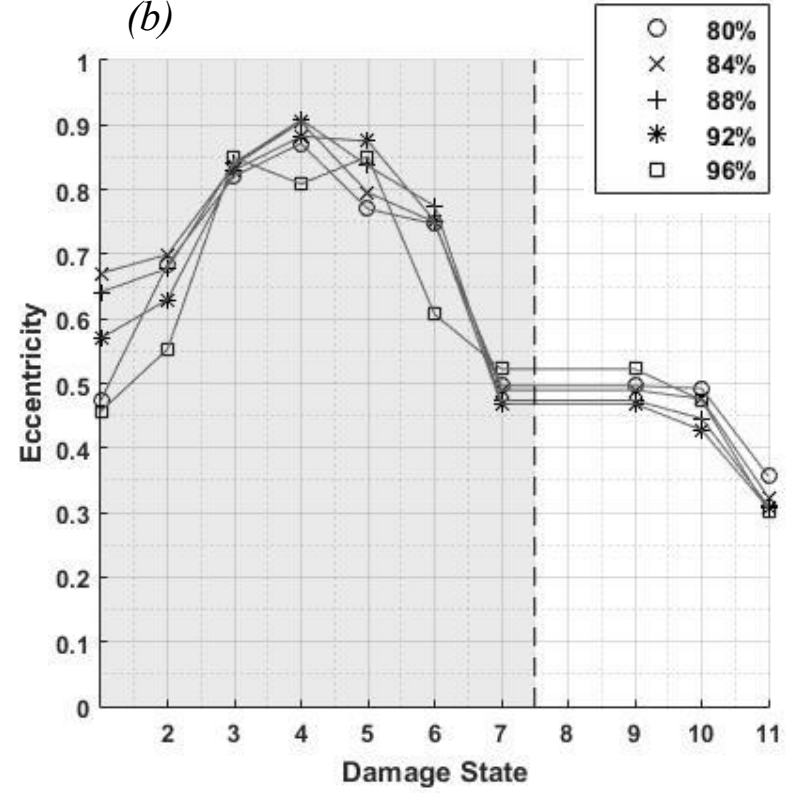

Figure 17: Eccentricity factor of images obtained with the pristine signals as baseline and: (a) without the signals being normalised, (b) with the signals being normalised. The grey region corresponds to data related defect 1 and the white region corresponds to data related to defect 2. It must be noted for damage state 8 defect 2 was not detected.

The difference between the area of the shape representing the defect in the images and that of actual defect is shown in Figure 18. The area ratio is defined as the area of the detected defect pattern in the image (with a segmentation threshold set at 92\%) divided by the calculated area of the actual induced damage. This was determined for each damage state. Figure 18a represents the area ratio determined from images that were processed without using the normalised signals; while results in Figure 18b show results for images processed using normalised signals. The area ratio shows that the image reconstruction processes systematically overestimate the size of the smallest damage. As the area of an actual defect increases the area of its related defect pattern in the reconstructed image becomes more accurate. Still, the most accurate area estimation that was found for damage state $6(10 \mathrm{~mm}$ hole) remains around five times larger than the area of the actual defect. These results show that the system has no difficulty detecting and locating even the smallest damage investigated, i.e. a $2 \mathrm{~mm}$ hole, but it remains difficult to accurately and consistently predict its true size. It is not yet possible to detect the resin micro cracking $[38,39]$ that may develop in off- 
axis plies and could lead to large delamination [40] that can trigger fibre fracture and ultimate failure. The positive aspect though is that for the damage cases examined, in no case the defect size was underestimated with the methodology followed.

(a)

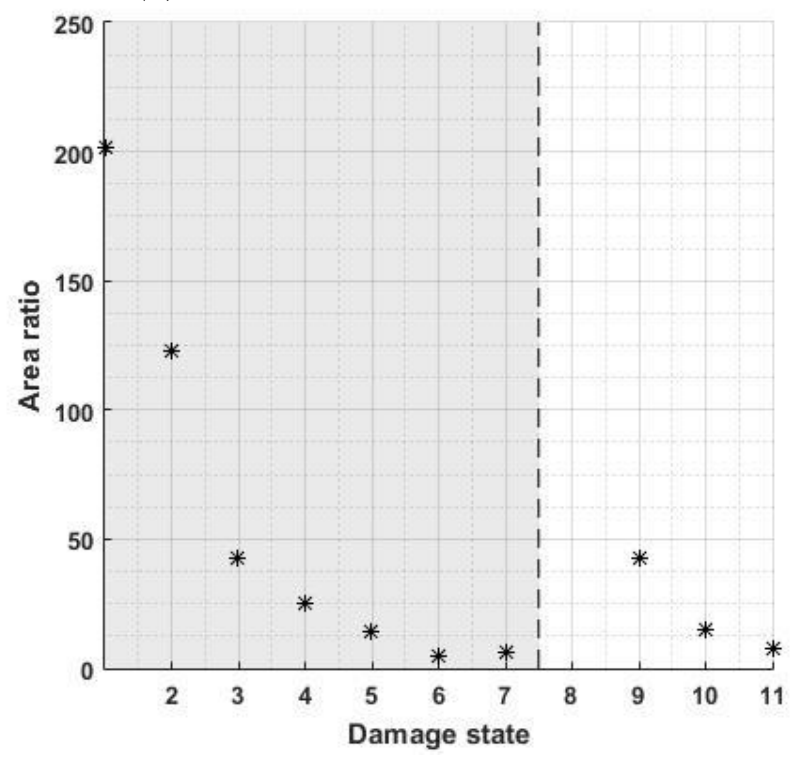

(b)

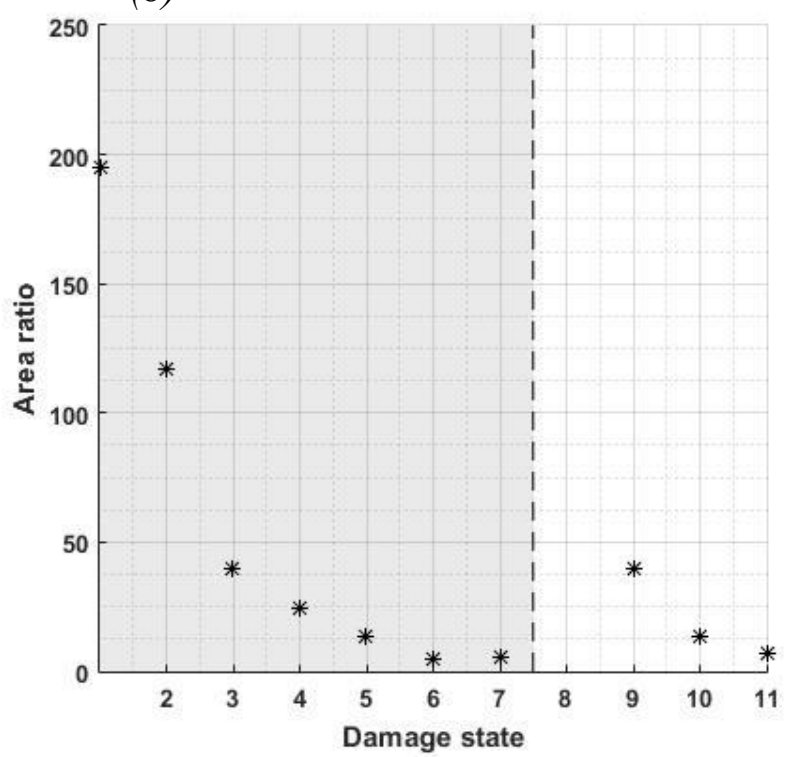

Figure 18: Graphs showing the area ratio, corresponding to that of the reconstructed defect shape with a 92\% segmentation threshold over the measured area of the actual defect, obtained from images with the pristine signals as baseline and: (a) without the signals being normalised, (b) with the signals being normalised. The grey region corresponds to data related defect 1 and the white region corresponds to data related to defect 2. It must be noted for damage state 8 defect 2 was not detected.

\section{Summary and conclusion}

In this extensive experimental campaign and rigorous study, the ability of an image reconstruction technique applied to guided wave signals in assessing the damage states of a large carbon fibre/epoxy composite plate was investigated. The composite plate was fitted with a permanent circular array of piezoelectric transducers. The guided wave signals were collected in pitch and catch configuration and tuned on the fundamental symmetric mode. Several defects in the type of holes and cracks of varying sizes were successively introduced in the structure, including one defect that was introduced outside the circular array of the bonded PZT transducers. The first guided wave signals collection was performed on the plate in its pristine (undamaged) condition. Thereafter plate inspection with guided waves was performed following the introduction of each defect, leading to the acquisition of twelve data sets each representing a different damage state.

Eight different methods of signal processing for the image reconstruction were investigated, all involving the Total Focusing Method with full matrix capture. The eight methods resulted from the combinations of three possible variations occurring at different stages in the signal processing algorithm: (i) the use of either the pristine signals or the signals from the previous damage state as the baseline; (ii) the use or non-use of normalised signals amplitude; (iii) the use or non-use of a 
lower threshold limit effectively excluding the negative amplitude in the signal waveform from contributing to the image reconstruction. The resulting images have shown that only the four processing methods involving the use of a lower threshold limit were best able to identify small open hole and crack like defects. The peculiarity of these methods was that they used only the waveform positive amplitudes in the image reconstruction. Their success was attributed to the fact that they prevented destructive interferences happening between the local minima in the signal waveform caused by wave attenuation (due to the presence of the defect) and the local maxima caused by wave scattering from the defect. Instead, only the information brought by waves scattering was preserved for the image reconstruction. Images obtained using the previous damage state signal as baseline could consistently detect and locate the evolution of already existing defects or the appearance of new defects, including the ones located outside the array of sensors. Most defects could be detected in images obtained using the pristine signals as baseline except for two case scenarios. In the first case of failed detection, two defects were present in the plate and only the largest one could be identified. In the second case of failed detection three defects were present and only the defect situated outside the array of sensors could not be detected.

Zoomed images were obtained in order to improve the resolution around the damaged regions of the plate. Analysis of the zoomed images was performed in an attempt to classify the defect type and estimate their size based on the images. The circularity and eccentricity factors as well as the area ratio between the imaged defect and the actual defect were calculated for each damage state. Circularity and eccentricity factors of images reconstructed using normalised signals and the pristine signals as baseline in their processing enabled a better defect classification between hole and crack type of defects. Crucially, each defect was identified and accurately located. The defect classification was inaccurate for the smallest hole-type defect (up to $2.5 \mathrm{~mm}$ in diameter) but was possible for a larger defect. Finally analysis of the area ratio showed that the image reconstruction algorithm systematically overestimated the size of the defect. This overestimation was intensified in the case of small defects. Crucially no defect size was underestimated and all defects were accurately located within the acceptable error range defined. In future work shape factors could be used as quantitative comparison between the defect shapes and, in conjunction with a database (of real or simulated defect shapes), contribute to the automation of the defect characterization procedure.

\section{Acknowledgements}

The authors wish to thank the Digital Signal Processing research group directed by Prof. Patrick Gaydecki at the University of Manchester for giving access to their laboratory equipment and helpful discussions and comments on this work. We thank Alma Rebeca Velasco Olmos and Neha Chandarana for programing the NI PXI system used for the data acquisition. Finally, the first author 
would like to acknowledge the University of Manchester Aerospace Research Institute for financially supporting her $\mathrm{PhD}$ studies.

\section{List of references}

[1] Giurgiutiu V and Soutis C 2012 Enhanced composites integrity through structural health monitoring Appl. Compos. Mater. 19 813-29

[2] Croxford A J, Wilcox P D, Drinkwater B W and Konstantinidis G 2007 Strategies for guided-wave structural health monitoring Proc. R. Soc. A Math. Phys. Eng. Sci. 463 2961-81

[3] Kessler S S, Spearing S M and Soutis C 2002 Damage detection in composite materials using Lamb wave methods Smart Mater. Struct. 11 269-78

[4] Willberg C, Koch S, Mook G, Pohl J and Gabbert U 2012 Continuous mode conversion of Lamb waves in CFRP plates Smart Mater. Struct. 21075022

[5] Gresil M and Giurgiutiu V 2014 Prediction of attenuated guided waves propagation in carbon fiber composites using Rayleigh damping model J. Intell. Mater. Syst. Struct.

[6] Worden K, Farrar C R, Manson G and Park G 2007 The fundamental axioms of structural health monitoring Proc. R. Soc. A Math. Phys. Eng. Sci. 463 1639-64

[7] Liu Y and Nayak S 2012 Structural health monitoring: State of the art and perspectives Jom $64789-92$

[8] Li J and Hao H 2016 A review of recent research advances on structural health monitoring in Western Australia Struct. Monit. Maint. 3 33-49

[9] Pfeiffer H and Wevers M 2007 Aircraft integrated Structural Health Assessment - Structural Health Monitoring and its implementation within the European project AISHA EU Project Meeting on Aircraft Integrated Structural Health Assessment (AISHA) pp 1-9

[10] Hayo T, Frankenstein B, Boller C and Bockenheimer C 2011 Approach To the Technical Qualification of a Shm System in Terms of Damage Detection in Aerospace Industry 2011 Cansmart Cinde Izfp

[11] Sharif-Khodaei Z and Aliabadi M H 2014 Assessment of delay-and-sum algorithms for damage detection in aluminium and composite plates Smart Mater. Struct. 2375007

[12] Fei Yan, Royer R L and Rose J L 2010 Ultrasonic Guided Wave Imaging Techniques in Structural Health Monitoring J. Intell. Mater. Syst. Struct. 21 377-84

[13] Fromme P, Thompson D O and Chimenti D E 2008 Monitoring of Plate Structures Using Guided Ultrasonic Waves AIP Conf. Proc. 975 78-85

[14] Michaels J E 2008 Detection, localization and characterization of damage in plates with an in situ array of spatially distributed ultrasonic sensors Smart Mater. Struct. 17

[15] Salmanpour M, Sharif Khodaei Z and Aliabadi M 2016 Guided wave temperature correction methods in structural health monitoring J. Intell. Mater. Syst. Struct. 1-15 
[16] Michaels J E and Michaels T E 2007 Guided wave signal processing and image fusion for in situ damage localization in plates Wave Motion 44 482-92

[17] Muller A, Robertson-Welsh B, Gaydecki P, Gresil M and Soutis C 2017 Structural Health Monitoring Using Lamb Wave Reflections and Total Focusing Method for Image Reconstruction Appl. Compos. Mater. 24 553-73

[18] Salmanpour M S, Khodaei Z S and Ferri Aliabadi M H 2017 Impact damage localisation with piezoelectric sensors under operational and environmental conditions Sensors (Switzerland)

[19] Kudela P, Radzienski M, Ostachowicz W and Yang Z 2018 Structural Health Monitoring system based on a concept of Lamb wave focusing by the piezoelectric array Mech. Syst. Signal Process. 108 21-32

[20] Diamanti K, Hodgkinson J M and Soutis C 2004 Detection of Low-velocity Impact Damage in Composite Plates using Lamb Waves Struct. Heal. Monit. 3 33-41

[21] Gresil M and Giurgiutiu V 2013 Guided wave propagation in composite laminates using piezoelectric wafer active sensors R. Soc. Aeronaut. J. 117 971-95

[22] Gresil M and Giurgiutiu V 2013 Time-domain hybrid global-local concept for guided-wave propagation with piezoelectric wafer active sensor J. Intell. Mater. Syst. Struct. 24 1897-911

[23] Mook G, Willberg C, Gabbert U and Pohl J Lamb wave mode conversion in CFRP plates

[24] Sharif Khodaei Z S, Qu L and Aliabadi M H 2013 Influence of adhesive layer on actuation of Lamb wave signals Key Eng. Mater. 525-526 617-20

[25] Hall J S and Michaels J E 2015 Multipath ultrasonic guided wave imaging in complex structures Struct. Heal. Monit. An Int. J. 14 345-58

[26] Muller A, Robertson-Welsh B, Gaydecki P, Gresil M and Soutis C 2016 Lamb Waves Boundary Reflections in an Aluminium Plate for Defect Detection related to Structural Health Monitoring 8th European Workshop On Structural Health Monitoring (Bilbao, Spain)

[27] Salmanpour M S, Sharif Khodaei Z and Aliabadi M H 2016 Airborne transducer integrity under operational environment for structural health monitoring Sensors (Switzerland) 16

[28] Salmanpour, M. S., Sharif-Khodaei, Z., Aliabadi M H 2017 Impact Damage Localisation with Piezoelectric Sensors under Operational and Environmental Conditions Sensors (Switzerland)) 17

[29] Zhang J, Wedge S, Rogerson A and Drinkwater B 2015 Comparison of ultrasonic image features with echodynamic curves for defect classification and characterization 41st Annu. Rev. Prog. Quant. Nondestruct. Eval. (AIP Conf. Proc. 1650) 1650 970-7

[30] Olive R, Wolf S, Dubreuil A, Bormuth V, Debrégeas G and Candelier R 2016 Rheotaxis of Larval Zebrafish: Behavioral Study of a Multi-Sensory Process Front. Syst. Neurosci. 10

[31] Khademi A, Moody A R and Venetsanopoulos A 2014 Accurate Pathology Segmentation in FLAIR MRI for Robust Shape Characterization Shape Analysis in Medical Image Analysis 
vol 14 pp 187-227

[32] Ng B, Toews M, Durrleman S and Shi Y 2014 Shape Analysis for Brain Structures Shape Analysis in medical Image Analysis vol 14 pp 3-49

[33] Kim T Y, Jang I H, Han D Y and Lee W G 2017 Quantitative image analysis of the shape and size of circular wound sites generated by vertically stamped scratches Micron 101 54-61

[34] Zhang D and Lu G 2004 Review of shape representation and description techniques Pattern Recognit. 37 1-19

[35] Saad M, Sadoudi A, Rondet E and Cuq B 2011 Morphological characterization of wheat powders, how to characterize the shape of particles? J. Food Eng. 102 293-301

[36] Hughes I G and Hase T P A 2010 Measurements and their uncertainties : a practical guide to modern error analysis Measurements and their uncertainties : a practical guide to modern error analysis vol 1 (Oxford : Oxford University Press) pp 1-8

[37] Dunkelberger K A and Mitchell O R 1985 Contour tracing for precision measurement Proc. - IEEE Int. Conf. Robot. Autom. 22-7

[38] Katerelos D T G, Kashtalyan M, Soutis C and Galiotis C 2008 Matrix cracking in polymeric composites laminates: Modelling and experiments Compos. Sci. Technol. 68 2310-7

[39] Kashtalyan M Y and Soutis C 2002 Mechanisms of internal damage and their effect on the behavior and properties of cross-ply composite laminates Int. Appl. Mech. 38 641-57

[40] Kashtalyan M, Zhang J and Soutis C 2002 Analysis of local delamination in composite laminates with cross ply matrix cracks 39 1393-8 